\title{
Incorporação de lodo de estação de tratamento de água (ETA) como agregado miúdo em concretos: avaliação das propriedades físico-mecânicas
}

\author{
Use of water treatment sludge (WTS) as \\ fine aggregate in concretes: evaluation \\ of physical-mechanical properties
}

\author{
Denis Meira Buselatto ${ }^{1}$, Matheus Chirardia Wenzel ${ }^{1}$, Gabriela Holsbach da Rocha ${ }^{1}$, \\ Jeferson Webber ${ }^{2}$, Sérgio Roberto da Silva ${ }^{3}$, Jairo José de Oliveira Andrade ${ }^{4}$
}

\footnotetext{
${ }^{1}$ Curso de Engenharia Civil - Escola Politécnica da PUCRS - Av. Ipiranga, 6681, Prédio 30, Parternon, Porto Alegre, Rio Grande do Sul, Brasil.

${ }^{2}$ Programa de Pós-Graduação em Engenharia Metalúrgica e Materiais - UFRGS, Porto Alegre, Rio Grande do Sul, Brasil.

${ }^{3}$ Eng. Civil, M.Sc. Doutorando do Programa de Pós-Graduação em Engenharia e Tecnologia de Materiais - PGETEMA/PUCRS - Av. Ipiranga, 6681, Prédio 30, Parternon, Porto Alegre, Rio Grande do Sul, Brasil.

${ }^{4}$ Professor do Programa de Pós-Graduação em Engenharia e Tecnologia de Materiais - PGETEMA/PUCRS - Av. Ipiranga, 6681, Prédio 30, Parternon, Porto Alegre, Rio Grande do Sul, Brasil.

e-mail: denis.buselatto@acad.pucrs.br, matheus.wenzel@acad.pucrs.br, gabriela.holsbach@acad.pucrs.br, webber.eng@gmail.com, jairo.andrade@pucrs.br, sergio.roberto@acad.pucrs.br
}

\section{RESUMO}

O presente trabalho tem como objetivo principal investigar a potencialidade do emprego de lodo de estação de tratamento de água (ETA) moído e calcinado em substituição ao agregado miúdo em concretos de cimento Portland, assim evitando o descarte em aterros sanitários e se tornando uma possível alternativa de reutilização desse material. Foram avaliados os efeitos dos teores de substituição de areia pelo lodo de ETA $(2,5 \%$, $5 \%, 7,5 \%$ e $10 \%$ em massa) e da relação a/c $(0,4,0,5$ e 0,6$)$ nas propriedades físicas (massa específica, porosidade e absorção de água por imersão) e mecânicas (resistências à compressão axial e à tração por compressão diametral) em diferentes idades (7, 28 e 91 dias). Todos os dados coletados foram analisados estatisticamente, empregando-se a análise de variância (ANOVA). Os resultados mostraram que, apesar da minimização das propriedades em comparação com o concreto de referência, todos os concretos apresentaram valores de resistência à compressão maiores que $25 \mathrm{MPa}$, considerando a maior relação a/c $(0,60)$. Sendo assim, com uma dosagem adequada poder-se-á inserir o material em concretos, se consideradas apenas as propriedades analisadas. De uma forma geral, o presente estudo mostra que o lodo de ETA pode ser empregado como agregado miúdo em concretos, sendo uma alternativa válida e sustentável para uso na construção.

Palavras-chave: Sustentabilidade, concreto, lodo de Estação de Tratamento de Água (ETA), propriedades mecânicas.

\section{ABSTRACT}

The present work has an objective to investigate the use of water treatment plant sludge (WTS) as fine aggregate in concretes. Were evaluated the effects of different sand replacement levels $(2.5 \%, 5 \%, 7.5 \%$ and $10 \%$ by mass) by WTS and the w/c ratio $(0.4,0.5$ and 0.6$)$ in physical (bulk density, porosity and water absorption by immersion) and mechanical properties (compressive and splitting tensile strength) at different ages (7, 28 and 91 days). All the collected data were statistically analyzed using analysis of variance (ANOVA). The results showed that, despite the minimization of the properties in comparison with the reference concrete, all concretes showed values of compressive strength greater than $25 \mathrm{MPa}$ at 91 days considering the highest w/c ratio (0.60). Therefore, the WTS can be used in concretes, considering the properties analyzed. In this way, the present study shows that the WTS can be used as fine aggregate in concrete, being a valid and sustainable alternative for use in construction. 
Keywords: Sustainability, Concrete, Water Treatment Sludge (WTS), Mechanical properties.

\section{INTRODUÇÃO}

É notável que, nos dias atuais, o consumo de materiais vem crescendo juntamente ao aumento da população, sem contar os descartes que são realizados de maneira excessiva no meio ambiente. No final do século XX, o conceito de desenvolvimento sustentável foi introduzido, e assim pôde-se avaliar a sustentabilidade no setor da construção civil [1]. Devido à grande demanda de materiais de construção, como resultado do desenvolvimento, há a necessidade de se obter materiais de diferentes fontes [2], e como consequência, tem-se o impacto ambiental, que é uma mudança do comportamento do meio ambiente causada pela ação do homem, prejudicando não só a natureza, mas também a vida da população. Paralelamente a isto, há a questão de que a indústria da construção civil consome grande parte dos materiais da natureza, e é geradora da maioria do descarte em aterros sanitários $[3,4]$

A produção de cimento vem se agravando desde o século XIX e, todo ano, a indústria cimentícia é responsável por aproximadamente 5-8\% da emissão mundial de $\mathrm{CO}_{2}$, provocando um impacto ambiental significativo [5]. Entretanto, algumas restrições estão sendo impostas para o consumo deste aglomerante, devido à necessidade de redução da emissão de $\mathrm{CO}_{2}$ e pelo alto custo de energia que é utilizada pela indústria cimentícia [6,7]. Porém, por ser grande consumidora de recursos e materiais, a construção civil se torna um setor com enorme potencial para a reutilização dos resíduos gerados por suas próprias atividades e de outros setores [8-10].

Aliado a tal fato tem-se que a demanda por água potável vem aumentando a cada ano, levando consequentemente a um aumento da quantidade de lodo gerado nas estações de tratamento de água (ETA). Nesses locais a água é captada de alguma fonte, muitas vezes de rios, onde passa por diversos processos para sua purificação (coagulação, floculação, decantação, filtração e desinfecção) [11]. O lodo é finalizado no processo de decantação, resultando da floculação de impurezas da água, assentando-se no fundo dos tanques de água e retirado em períodos de limpeza dos mesmos, representando de 0,3 a $1 \%$ do volume da água tratada[12]. O material ainda pode ser centrifugado para retirada da água em excesso (voltando à estação), mas sem nenhum tipo de tratamento adicional, para posteriormente ser descartado em aterros ou em corpos d'água, não sendo uma opção de disposição ambientalmente correta, sendo essa prática comprometedora da qualidade da água potável e a saúde do público e animais que a utilizam [13,14]. O descarregamento de lodo em corpos d'água conduz ao aumento acumulativo das concentrações de alumínio na água, nos organismos aquáticos, e consequentemente, nos corpos humanos [11]. O lodo de ETA é classificado como resíduo sólido Classe II A - não inerte, e deve ser disposto segundo a NBR 10004 [15], cujo mesmo pode conter na sua composição materiais inertes, matéria orgânica e alguns precipitados químicos, como compostos de alumínio e ferro em quantidades significativas [16,17].

No que se refere à disposição final deste resíduo, entre as alternativas mais conhecidas destacam-se a aplicação em solo, a destinação em aterro sanitário, a incineração e a utilização como matéria-prima em algumas indústrias, como a construção civil [12,18,19]. Dentro desse contexto, já foram realizados alguns estudos visando verificar a potencialidade do reaproveitamento do resíduo de lodo de ETA na construção, conforme citado por diversos pesquisadores. MONTEIRO et al. [20] verificaram que o emprego de $10 \%$ do material aumentou levemente a absorção d'água e minimizou as propriedades mecânicas após o processo de calcinação das argilas. O lodo de ETA também pode ser uma alternativa ao emprego da argila na fabricação de tijolos, cujas propriedades microestruturais (DRX, microscopia eletrônica e investigações mineralógicas) foram empregadas para verificar o comportamento do material após o processo de sinterização $\left(\mathrm{t}=1000^{\circ} \mathrm{C}\right)$. Gastaldini et al. [16] investigaram a influência do tempo e da temperatura de calcinação na atividade pozolânica do lodo de ETA, cujos autores concluíram que a queima a uma temperatura de $600^{\circ} \mathrm{C}$ por 1 hora apresentou a melhor relação entre a resistência obtida e a energia necessária para a obtenção de um material com características pozolânicas adequadas. FRÍAS et al. [21] substituíram $15 \%$ do teor de cimento por lodo de ETA calcinado a uma temperatura de $600^{\circ} \mathrm{C}$ por 2 horas em argamassas. Os autores constataram um decréscimo de $16 \%$ na resistência à compressão aos 28 dias em relação aos exemplares de referência. YAGÜE et al. [22] verificaram que a adição de lodo de ETA em concretos reduz a resistência à compressão. Todavia, considerando algumas propriedades associadas com a durabilidade (ciclos de molhagem e secagem - em água, água do mar e água com sulfatos -, cura acelerada em autoclave e carbonatação acelerada) o desempenho dos concretos com lodo de ETA foi considerado aceitável em comparação aos concretos de referência. Jamshidi, et al. [23] também observaram que concretos com teores de substituição entre 5\% e $10 \%$ apresentaram uma pequena diminuição da resistência à compressão no tempo. Ramirez [24] verificou que a adição de lodo in natura (também denominado de lodo úmido) tende a reduzir a resistência do concreto. Todavia, o autor cons- 
tatou que um teor de 5\% de resíduo melhora as propriedades mecânicas dos concretos, considerando o concreto moldado com lodo calcinado. SALES et al. [25] incorporaram lodo de ETA com resíduos moídos de materiais provenientes da construção civil para a utilização em argamassa e concreto de cimento Portland. Os autores verificaram que a adição de $3 \%$ de lodo em relação aos agregados miúdos apresentou uma redução insignificante da resistência mecânica comparada ao concreto usual, obtendo características semelhantes.

Dessa forma verifica-se que muitas pesquisas vêm investigando o emprego do lodo de ETA, principalmente na forma calcinada, como substituição ao cimento em concretos. Todavia, poucos estudos mostram a possibilidade da aplicação do material como agregado miúdo em concretos. Em função dos aspectos apresentados, o presente trabalho tem como objetivo principal estudar a potencialidade do emprego do lodo de ETA como agregado miúdo em concretos de cimento Portland. Como objetivos específicos podem ser citados: (i) analisar as propriedades físico-químicas do lodo de ETA; (ii) verificar a influência da relação a/c e do teor de substituição de agregado miúdo por lodo de ETA nas propriedades físicas e mecânicas dos concretos; (iii) modelar o comportamento das propriedades analisadas, empregando-se a análise de variância (ANOVA).

\section{MATERIAIS E MÉTODOS}

\subsection{Materiais}

Para o procedimento experimental foi utilizado o cimento Portland CP V-ARI, que apresenta o menor teor de adições dentre os cimentos disponíveis comercialmente, cujo mesmo segue as prescrições da NBR 5733 [26]. A distribuição granulométrica do cimento Portland foi obtida através do analisador de partículas Cilas

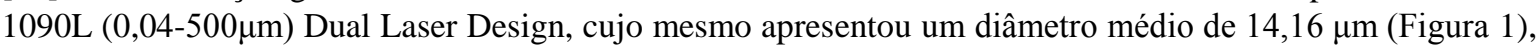
compatível com um cimento de alta resistência inicial, em função da sua elevada finura.

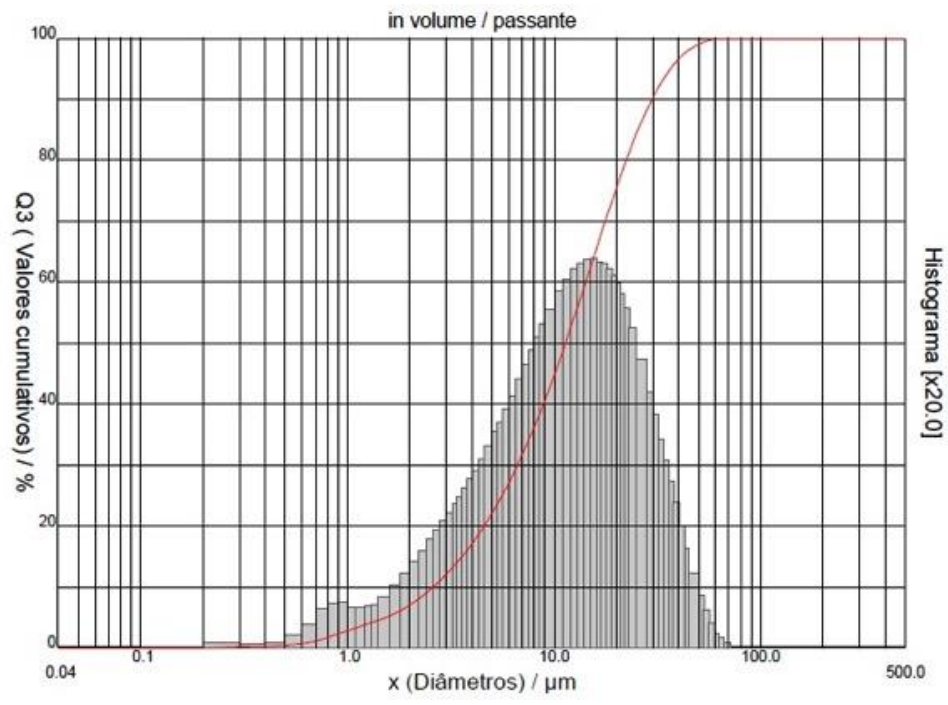

Figura 1: Distribuição granulométrica do cimento Portland CP V ARI

As características físicas do cimento encontram-se apresentadas na Tabela 1 , cujo mesmo atende às exigências indicadas na NBR 5733 [26]. 
Tabela 1: Caracterização física do cimento CP V ARI

\begin{tabular}{|c|c|c|}
\hline \multicolumn{2}{|l|}{ ENSAIO } & RESULTADO \\
\hline \multicolumn{2}{|l|}{ Resíduo \# 200} & $0,07 \%$ \\
\hline \multicolumn{2}{|l|}{ Resíduo \# 325} & $0,48 \%$ \\
\hline \multicolumn{2}{|l|}{ Expansibilidade à quente } & $0,35 \mathrm{~mm}$ \\
\hline \multicolumn{2}{|l|}{ Peso específico } & $3,09 \mathrm{~g} / \mathrm{cm}^{3}$ \\
\hline \multicolumn{2}{|l|}{ Superfície específica (Blaine) } & $4428 \mathrm{~cm}^{2} / \mathrm{g}$ \\
\hline \multirow{3}{*}{ Resistência mecânica (MPa) } & 3 dias & 38,2 \\
\hline & 7 dias & 44,2 \\
\hline & 28 dias & 51,6 \\
\hline
\end{tabular}

O lodo de ETA empregado foi coletado da estação de tratamento de água (ETA) em estado in natura na Companhia Rio-grandense de Saneamento (CORSAN) do município de Gravataí/RS, cujo material recebido possuía consistência pastosa. A CORSAN utiliza uma grande área à céu aberto para o armazenamento destes resíduos sólidos e para fim de descarte fornecer este material gratuitamente. Foi realizada a secagem do lodo em uma estufa por $24 \mathrm{~h}$ a uma temperatura de $110^{\circ} \mathrm{C}$, moído em um moedor vertical com pás circulares por 4 minutos e calcinado em um forno na temperatura de $600^{\circ} \mathrm{C}$ por $1 \mathrm{~h}$. Na Figura 2 é possível visualizar o lodo de ETA no estado in natura (a), seco em estufa (b) e calcinado (c).

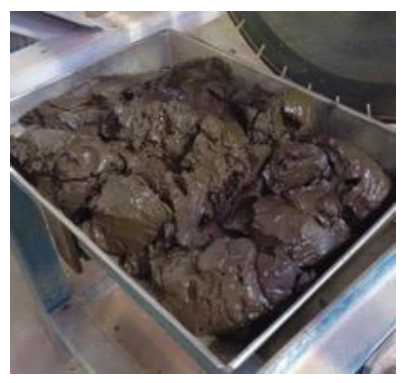

(a)

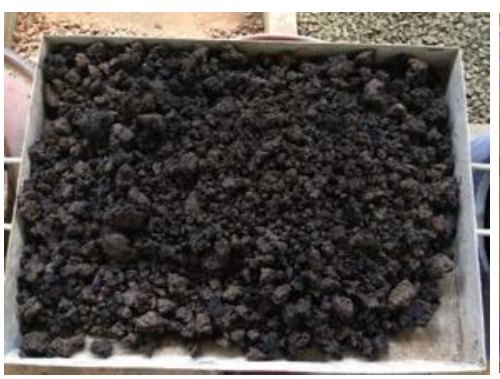

(b)

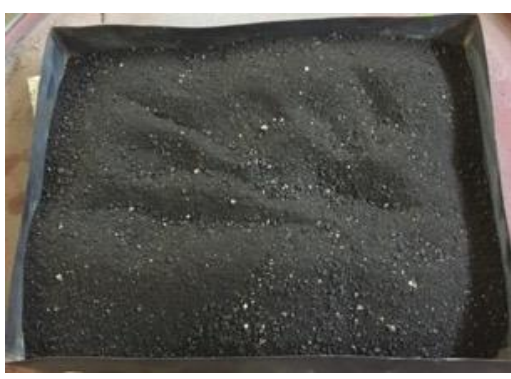

(c)

Figura 2: Lodo de ETA in natura (a); Lodo de ETA seco em estufa (b); Lodo de ETA calcinado (c).

Para se determinar a temperatura desejável para a calcinação do lodo de ETA foi realizado o ensaio termogravimétrico (TGA) no forno modelo SDT Q600 V20.9 Biuld 20. Utilizou-se 18,5 g da amostra representativa de lodo de ETA, cujo resultado do ensaio está apresentado na Figura 3.

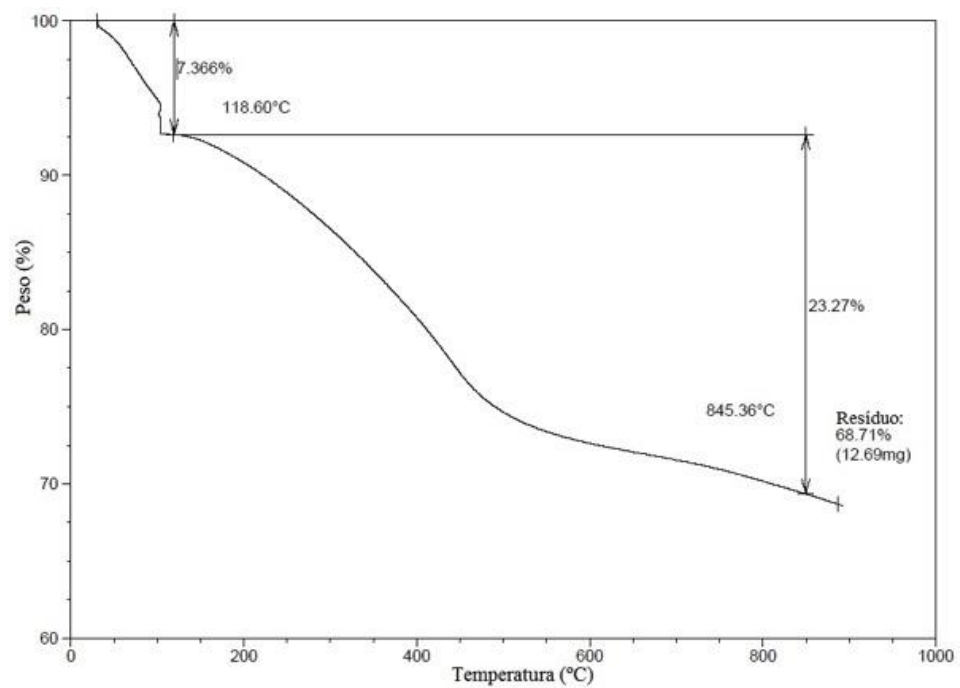

Figura 3: Ensaio termogravimétrico (TGA) do lodo de ETA 
As análises da curva de TGA mostraram uma perda de massa média de $31,7 \%$ entre 25 e $845^{\circ} \mathrm{C}$, principalmente em função da eliminação da água adsorvida, hidroxilas e decomposição da matéria orgânica. KIZINIEVIC et al. [27] encontraram valores de perda de massa igual a 22,5\% em um lodo de ETA na Lituânia, enquanto GODOY [28] determinou que tal parâmetro para um lodo de ETA da região de Blumenau (SC) foi igual a $16,3 \%$. Tais valores apresentam uma variação em função principalmente da heterogeneidade dos lodos de ETA investigados, em função tanto da região geográfica quanto dos processos adotados nas estações de tratamento.

Verifica-se na curva de TGA que para temperaturas entre $600^{\circ} \mathrm{C}$ e $800^{\circ} \mathrm{C}$ a perda de massa não é considerada significativa. De acordo com GASTALDINI et al. [16], a calcinação do lodo de ETA a uma temperatura de $700^{\circ} \mathrm{C}$ por 30 min e a uma temperatura de $600^{\circ} \mathrm{C}$ por $1 \mathrm{~h}$ cumpre todos os requisitos especificados pela NBR 15894 [29] para materiais pozolânicos, com menor consumo energético. Com base nestas informações estabeleceu-se, para este ensaio, a calcinação do lodo de ETA a uma temperatura de $600^{\circ} \mathrm{C}$ por $1 \mathrm{~h}$.

Para a realização do ensaio semiquantitativo por espectrometria de fluorescência de raios X (FRX) uma quantidade de $2 \mathrm{~kg}$ de lodo de ETA calcinado foi moída em um moinho vertical com pás circulares por 1 h. Após esse período foram coletadas $30 \mathrm{~g}$ do lodo passante na peneira com abertura de $75 \mu \mathrm{m}$ para a realização do ensaio. A composição química do cimento Portland e do lodo de ETA que estão apresentadas na Tabela 2 foram obtidas através do ensaio semiquantitativo por espectrometria de fluorescência de raios $\mathrm{X}$ (FRX), realizado no equipamento PANalytical Axios Max.

Tabela 2: Composição química do cimento e do lodo de ETA

\begin{tabular}{cccccccccc}
\hline & $\begin{array}{c}\mathrm{SiO}_{2} \\
(\%)\end{array}$ & $\begin{array}{c}\mathrm{Al}_{2} \mathbf{O}_{3} \\
(\%)\end{array}$ & $\begin{array}{c}\mathrm{Fe}_{2} \mathbf{O}_{3} \\
(\%)\end{array}$ & $\begin{array}{c}\mathbf{C a O} \\
(\%)\end{array}$ & $\begin{array}{c}\mathbf{M g O} \\
(\%)\end{array}$ & $\begin{array}{c}\mathbf{K}_{2} \mathbf{O} \\
(\%)\end{array}$ & $\begin{array}{c}\mathbf{S O}_{3} \\
(\%)\end{array}$ & $\begin{array}{c}\mathbf{N a}_{2} \mathbf{O} \\
(\%)\end{array}$ & $\begin{array}{c}\mathbf{P F} \\
(\%)\end{array}$ \\
\hline Cimento & 18,52 & 4,24 & 2,98 & 60,54 & 3,81 & 0,7 & 3,11 & 0,2 & 3,49 \\
\hline Lodo de ETA & 28,40 & 21,50 & 11,3 & 0,5 & 0,3 & 0,3 & 1,0 & 0,1 & 35,32 \\
\hline
\end{tabular}

$\mathrm{PF}=$ perda ao fogo

AHMAD et al. [13] analisaram a composição química do lodo de ETA da cidade industrial Ghaziabad do estado de Uttar Pradesh, na Índia. O material apresentou em maior percentagem o $\mathrm{SiO}_{2}(52,78 \%)$ e o $\mathrm{Al}_{2} \mathrm{O}_{3}(14,38 \%)$, também em menores proporções o $\mathrm{Fe}_{2} \mathrm{O}_{3}(5,20 \%), \mathrm{CaO}(4,39 \%)$ e o $\mathrm{K}_{2} \mathrm{O}(3,62 \%)$. VALLS et al. [30] realizaram o ensaio de caracterização química do lodo de estação de tratamento de esgoto (ETE) no estado calcinado, provindo do Rio Sec que está situado no município de Sabadell (Espanha), cujos resultados apresentaram em maiores proporções o $\mathrm{SiO}_{2}(29,7 \pm 0,2 \%)$, o $\mathrm{CaO}(22,7 \pm 0,2 \%)$, o $\mathrm{Al}_{2} \mathrm{O}_{3}(12,9 \pm$ $0,2 \%)$ e o $\mathrm{P}_{2} \mathrm{O}_{5}(12,4 \pm 0,2 \%)$.

Quando comparados os dados apresentados pode-se observar grande similaridade na composição química dos lodos de ETA e ETE, principalmente no óxido de silício que é o elemento com maior percentual nos estudos apresentados. Para analisar a forma das partículas do cimento Portland (Figura 4a) e no lodo de ETA (Figura 4b), utilizou-se o microscópio eletrônico de varredura (MEV), modelo XL 30, Philips, com tensão de trabalho entre 0,5 e $30 \mathrm{kV}$.

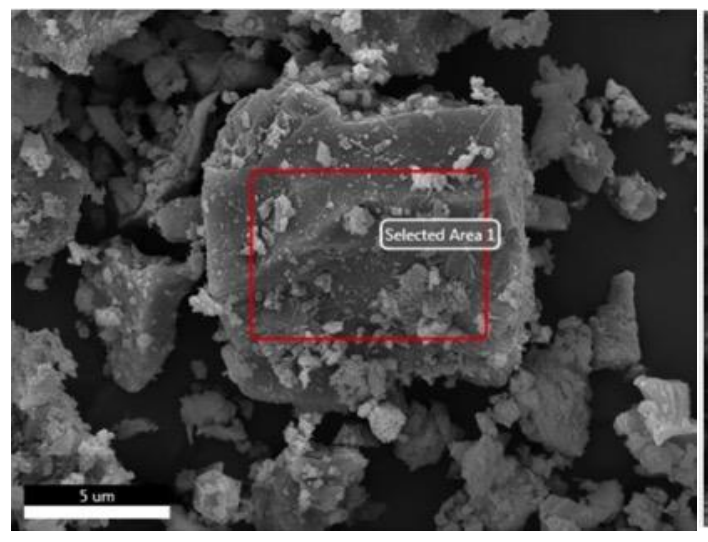

(a)

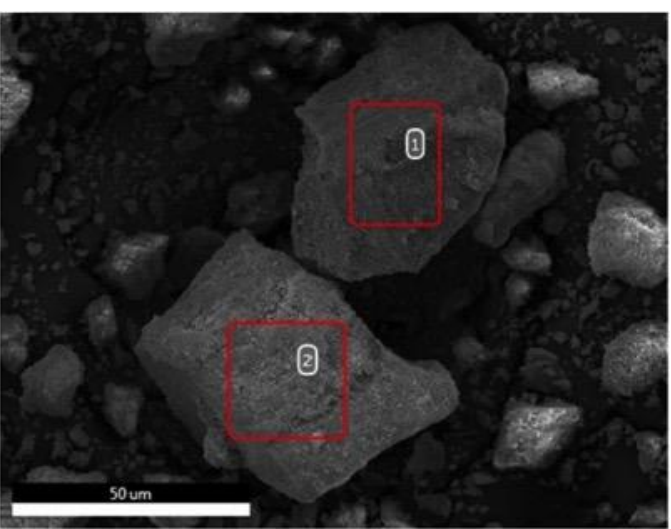

(b)

Figura 4: Forma das partículas do cimento Portland (a) e do lodo de ETA (b) 
Verifica-se que tanto o cimento Portland como o lodo de ETA apresentaram formas irregulares. RODRIGUEZ et al. [31] analisaram o tamanho das partículas do lodo de ETA, cujo resíduo apresentou grande variação no tamanho, cerca de 1 a $600 \mu \mathrm{m}$ e um tamanho médio de $5 \mu \mathrm{m}$.. Na Tabela 3 estão apresentados os elementos identificados através do EDS nas regiões apresentadas na Figura 4.

Tabela 3: Elementos presentes nas regiões marcadas na Figura 4

\begin{tabular}{l|l|l}
\hline ELEMENTO & CIMENTO (\%) & LODO DE ETA (\%) \\
\hline $\mathrm{C}$ & 30,67 & 25,93 \\
\hline $\mathrm{O}$ & 6,98 & 26,22 \\
\hline $\mathrm{Al}$ & 0,82 & 17,89 \\
\hline $\mathrm{Si}$ & 3,67 & 18,07 \\
\hline $\mathrm{Ca}$ & 34,93 & - \\
\hline $\mathrm{Fe}$ & 1,07 & 11,89 \\
\hline
\end{tabular}

A Figura 5 apresenta o ensaio de espectrometria de difração de raios X (DRX) do lodo de ETA e da areia.

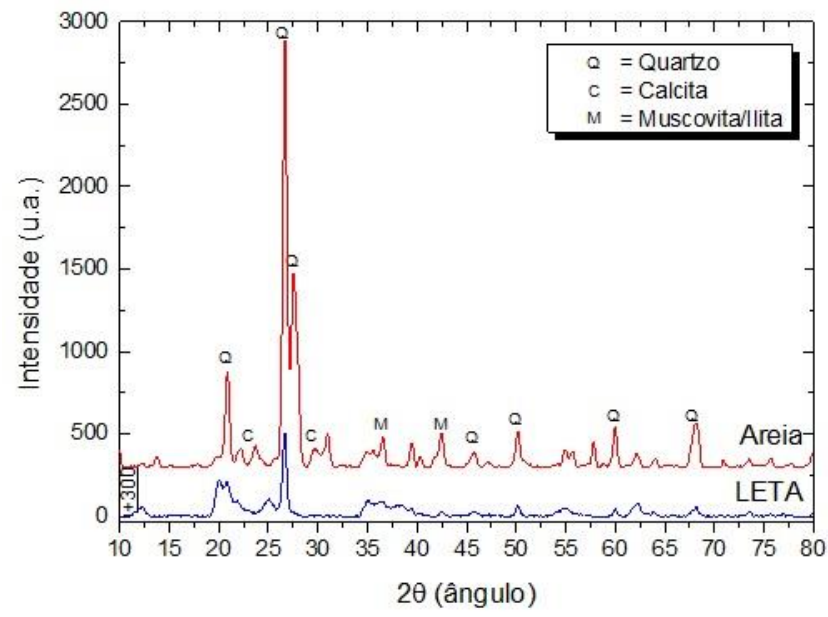

Figura 5: DRX do lodo de ETA e da areia.

Verifica-se a presença de quartzo, calcita, muscovita e ilita como as principais fases cristalinas na areia, enquanto que no lodo de ETA observa-se principalmente a presença dos picos de quartzo, conforme observado em outros trabalhos. Valls et al. [30] encontraram a presença de minerais inorgânicos como quartzo e calcita ao analisar o lodo de estação de tratamento de esgoto (ETE) empregado na sua investigação. GASTALDINI et al. [16] identificaram que o resíduo é composto em maior parte por quartzo e caulinita e, em quantidades menores, por feldspatos e hematita. Já GODOY [28] encontrou também picos de quartzo e caulinita, além de traços de muscovita e monganite.

Na Tabela 4 estão apresentados os resultados do ensaio de extrato lixiviado do resíduo sólido, contendo as concentrações de cada substância. $\mathrm{O}$ pH da solução à $25^{\circ} \mathrm{C}$ foi igual a 5,13 , valor este ligeiramente inferior à faixa de variação de 5,5 a 9,0 estabelecida pela NBR 15.900 [32]. 
Tabela 4: Parâmetros inorgânicos do lodo de ETA

\begin{tabular}{|c|c|c|c|c|}
\hline PARÁMETRO & LMEL (MG.L-1) & VME (MG.L-1) & RESULTADO & UNIDADE \\
\hline Ag - Prata & 5 & 0,01 & $<0,002$ & $\mathrm{mg} \mathrm{Ag/L}$ \\
\hline $\mathrm{Al}$ - Alumínio & NA & - & 102 & $\mathrm{mg} \mathrm{Al} / \mathrm{L}$ \\
\hline As - Arsênio & 1 & 0,01 & 0,006 & mg As/L \\
\hline Ba - Bário & 70 & 0,7 & 0,202 & $\mathrm{mg} \mathrm{Ba} / \mathrm{L}$ \\
\hline Cd - Cádmio & 0,5 & 0,001 & $<0,0006$ & $\mathrm{mg} \mathrm{Cd} / \mathrm{L}$ \\
\hline Co - Monóxido de Carbono & - & 0,05 & - & $\mathrm{mg} \mathrm{Co} / \mathrm{L}$ \\
\hline $\mathrm{Cr}-$ Cromo total & 5 & 0,05 & 0,066 & $\mathrm{mg} \mathrm{Cr} / \mathrm{L}$ \\
\hline $\mathrm{Cu}$ - Cobre & NA & 0,009 & $<0,006$ & $\mathrm{mg} \mathrm{Cu} / \mathrm{L}$ \\
\hline F- Fluoreto & 150 & - & 0,101 & $\mathrm{mg} \mathrm{F} / \mathrm{L}$ \\
\hline Hg - Mercúrio & 0,1 & - & 0,0022 & $\mathrm{mg} \mathrm{Hg} / \mathrm{L}$ \\
\hline Mn - Manganês & - & 0,1 & - & $\mathrm{mg} \mathrm{Mn} / \mathrm{L}$ \\
\hline $\mathrm{Ni}$ - Níquel & - & 0,025 & - & $\mathrm{mg} \mathrm{Ni} / \mathrm{L}$ \\
\hline $\mathrm{Pb}-$ Chumbo & 1 & 0,01 & $<0,004$ & $\mathrm{mg} \mathrm{Pb} / \mathrm{L}$ \\
\hline Se - Selênio & 1 & 0,01 & 0,009 & $\mathrm{mg} \mathrm{Se} / \mathrm{L}$ \\
\hline V - Vanádio & - & 0,1 & $<0,004$ & $\mathrm{mg} \mathrm{V} / \mathrm{L}$ \\
\hline Zn - Zinco & - & 0,18 & 0,039 & $\mathrm{mg} \mathrm{Zn/L}$ \\
\hline Massa específica & - & - & 0,858 & $\mathrm{~g} / \mathrm{mL}$ \\
\hline Umidade & - & - & 80 & $\%$ \\
\hline Matéria Orgânica & - & - & 43,5 & $\%$ \\
\hline $\begin{array}{l}\text { Sólidos Suspensos Totais } \\
\text { (SST) }\end{array}$ & - & - & $<2,00$ & $\mathrm{mg} \mathrm{SST/L}$ \\
\hline Sólidos Totais (ST) & - & - & 6466 & $\mathrm{mg} \mathrm{ST} / \mathrm{L}$ \\
\hline
\end{tabular}

LMEL: Limite máximo permitido no extrato lixiviado (mg.L-1) - NBR 10.004 [15]

VME: Valor máximo dos elementos (mg.L-1) em Rio Classe 2 - CONAMA 357 [33]

Através do ensaio de lixiviação com reagente ácido acético glacial (HOAc) p.a. e seguindo os procedimentos da NBR 10.004 [15] e NBR 10.005 [34], foi possível obter as concentrações de metais do lodo de ETA por meio do extrato lixiviado, a norma classifica esses resíduos sólidos como não perigosos e não inertes. Conforme os resultados apresentados na Tabela 5, pode-se perceber que os resultados atenderam aos limites máximos estabelecidos por norma. RAMIREZ et al. [35] salientam que os resultados encontrados no extrato lixiviado, em grande maioria, atendem ao limite aceitável pela legislação para rios de Classe 2 (Resolução CONAMA 357 [33]). VALLS et al. [30] empregaram a norma alemã DIN 38414-S4 para o ensaio de lixiviação e os resultados obtidos mostram que o lodo é um resíduo especial. O teor presente de níquel foi $1,06 \mathrm{mg} / \mathrm{l}$, que supera superficialmente o limite (1 mg/l) fixado em decreto 34/1996 pelo Governo da Catalunha.

A massa específica do lodo úmido foi igual a $0,858 \mathrm{~g} / \mathrm{cm}^{3}$, valor próximo ao da água $\left(1,0 \mathrm{~g} / \mathrm{cm}^{3}\right) \mathrm{em}$ função da elevada umidade do material (80\%), cujos valores são próximos àqueles encontrados por outros pesquisadores. RAMIREZ [35] encontrou um valor para umidade igual a 76\%, associado com uma densidade igual a $1,17 \mathrm{~g} / \mathrm{cm}^{3}$, enquanto que TAFAREL et al. [36] determinaram um teor de umidade igual a 86,5\%, associada a uma massa específica de $1,23 \mathrm{~g} / \mathrm{cm}^{3}$.

De acordo com os resultados encontrados pode-se verificar que o lodo de ETA empregado apresenta características bem similares àquelas encontradas em outros trabalhos aonde tal material foi incorporado nos materiais de construção civil, mostrando a potencialidade do uso do mesmo como agregados miúdos para concreto.

Como o estudo consiste em empregar o resíduo de lodo de ETA em substituição ao agregado miúdo natural, foi necessária a caracterização granulométrica de ambos os materiais. A granulometria do agregado graúdo natural, da areia natural e da areia reciclada proveniente do lodo de ETA, são apresentados na Figura 6, cujas propriedades físicas dos mesmos estão apresentadas na Tabela 5. Vale salientar que tais propriedades referem-se ao lodo de ETA após o processo de calcinação e moagem. 

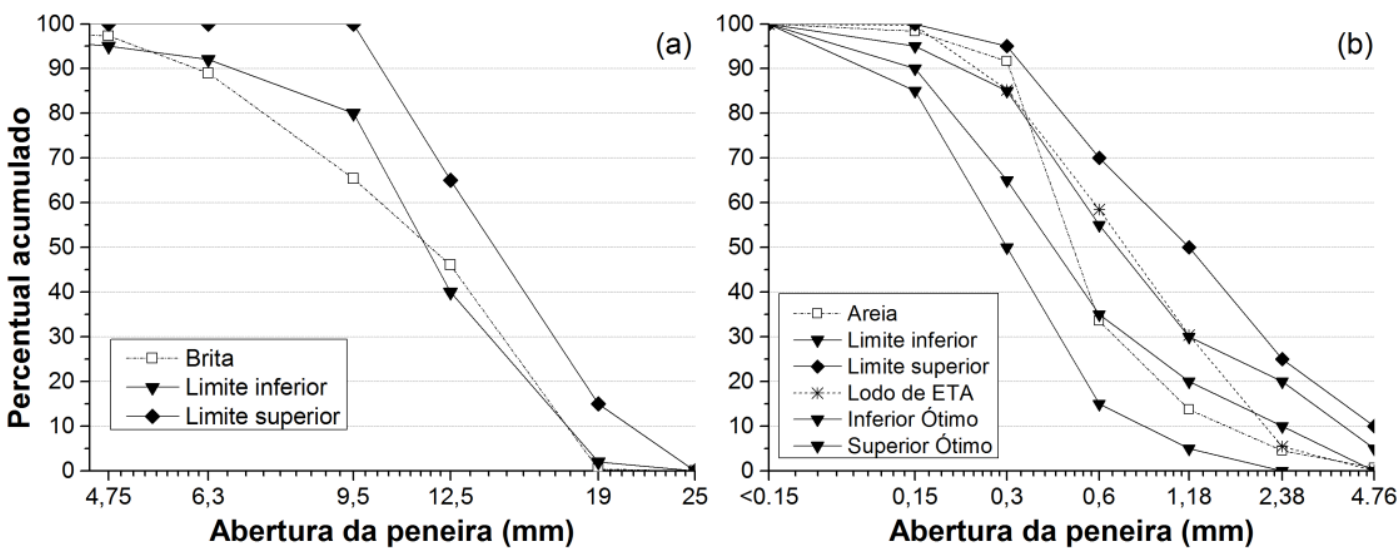

Figura 6: Distribuições granulométricas dos materiais: (a) agregado graúdo; areia natural e lodo de ETA (b).

Tabela 5: Caracterização física dos agregados

\begin{tabular}{l|l|l|l}
\hline PARÂMETROS & $\begin{array}{l}\text { AREIA NATU- } \\
\text { RAL }\end{array}$ & LODO DE ETA & $\begin{array}{l}\text { AGREGADO GRAÚDO } \\
\text { NATURAL }\end{array}$ \\
\hline Massa específica $\left(\mathrm{g} / \mathrm{cm}^{2}\right)$ & 2,61 & 2,16 & 2,85 \\
\hline Massa unitária $\left(\mathrm{g} / \mathrm{cm}^{3}\right)$ & 1,50 & 0,86 & 1,39 \\
\hline Módulo de finura & 1,89 & 2,75 & 2,77 \\
\hline Dimensão máxima $(\mathrm{mm})$ & 1,18 & 2,36 & 19 \\
\hline Absorção d'água $(\%)$ & 0,85 & 7,5 & 0,35 \\
\hline Origem do agregado & Rio Jacuí/RS & ETA Gravataí/RS & Porto Alegre/RS \\
\hline
\end{tabular}

\subsection{Planejamento do experimento e produção dos concretos}

Os parâmetros controláveis empregados no projeto experimental foram a relação a/c e o teor de substituição de agregado miúdo natural pelo lodo de ETA, conforme apresentado na Tabela 6.

Tabela 6: Níveis dos parâmetros controláveis empregados

\begin{tabular}{l|l}
\hline PARÂMETROS CONTROLÁVEIS & NIVEIS \\
\hline Teor de lodo de ETA & $0 \%, 2,5 \%, 5 \%, 7,5 \%$ e $10 \%$ \\
\hline Relação a/c & $0,4,0,5$ e 0,6 \\
\hline
\end{tabular}

Nesse caso, visando reduzir a quantidade de corpos de prova a serem moldados considerando o programa experimental proposto, optou-se por realizar um fracionamento do experimento. Tal técnica é útil quando se deseja uma otimização de tempo e recursos para a obtenção dos resultados, cuja mesma já foi empregada em diversos trabalhos $[9,10]$, com bons resultados.

Inicialmente foram feitas moldagens empregando-se o método IPT/EPUSP [37] visando determinar a curva de dosagem (Figura 7) para obter os concretos em função das relações a/c pré-determinadas no programa experimental $(0,4,0,5$ e 0,6). Foi fixado um abatimento de $90 \pm 10 \mathrm{~mm}$ e teor de argamassa $(\alpha)$ igual a $55 \%$ para todos os traços. 


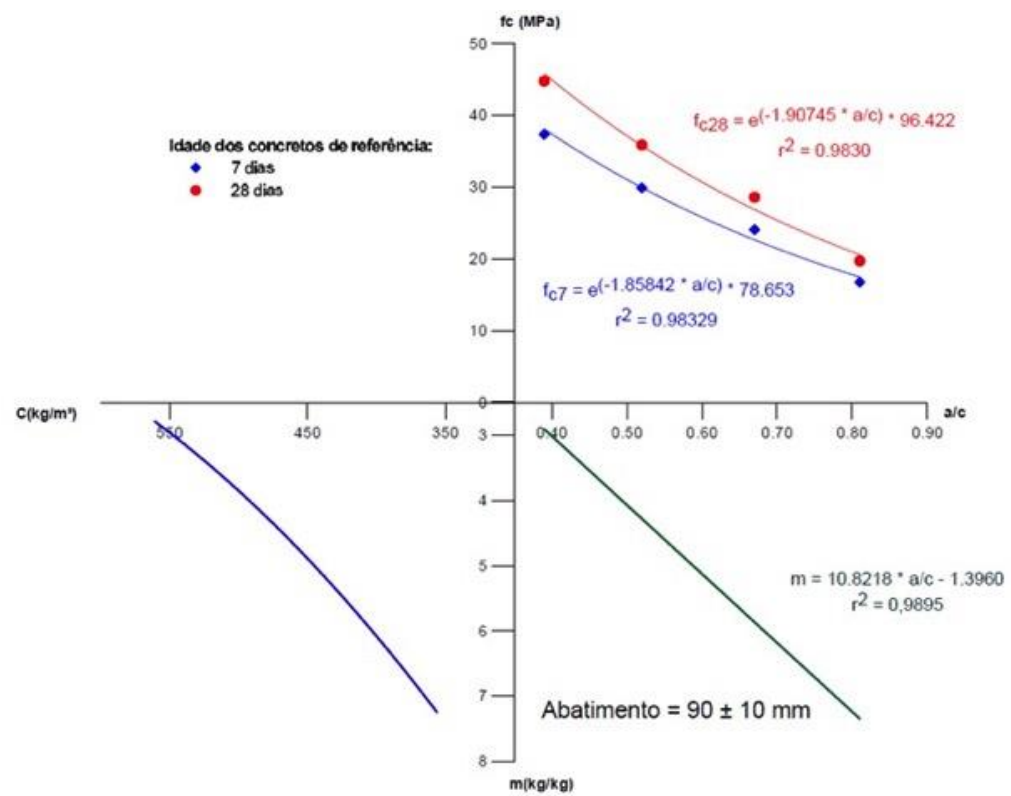

Figura 7: Diagrama de dosagem dos concretos de referência

Com base no diagrama de dosagem foram obtidos os traços com base nas relações a/c fixadas no programa experimental, cujos traços em massa dos concretos estão apresentados na Tabela 7.

Tabela 7: Proporcionamento dos concretos de referência

\begin{tabular}{c|r|r|r|r|r}
\hline $\begin{array}{l}\text { RELAÇÃO } \\
\text { a/c }\end{array}$ & \multicolumn{1}{l|}{$\mathbf{m}$} & a & p & H (\%) & C (kg/m $\mathbf{m}^{\mathbf{3}}$ \\
\hline 0,4 & 2,91 & 1,15 & 1,76 & 10,23 & 557 \\
\hline 0,5 & 4,0 & 1,75 & 2,25 & 10,00 & 435 \\
\hline 0,6 & 5,1 & 2,35 & 2,74 & 9,85 & 357 \\
\hline
\end{tabular}

Devido à diferença existente entre as massas específicas do agregado miúdo e o lodo de ETA, ao substituir o resíduo no lugar da areia, por possuir menor massa específica, implicaria em um volume maior de lodo, necessitando de uma maior demanda de água. Devido a isto optou-se pela realização da compensação em volume dos materiais, conforme empregado em outros trabalhos [9,10,38, 39] utilizando a Equação 1.

$$
M_{L E}=M_{A N} \times \frac{\gamma_{L E}}{\gamma_{A N}}
$$

Onde: $\mathrm{M}_{\mathrm{LE}}=$ massa do lodo de $\operatorname{ETA}(\mathrm{kg}) ; \mathrm{M}_{\mathrm{AN}}=$ massa do agregado natural $(\mathrm{kg}) ; \gamma_{\mathrm{LE}}=$ massa específica do lodo de ETA $\left(\mathrm{kg} / \mathrm{dm}^{3}\right)$ e $\gamma_{\mathrm{AN}}=$ massa específica do agregado natural $\left(\mathrm{kg} / \mathrm{dm}^{3}\right)$. Foi determinado que o lodo de ETA fosse empregado como substituição em massa em relação à areia natural, cujos traços executados encontram-se apresentados na Tabela 8.

Tabela 8: Traços empregados no programa experimental

\begin{tabular}{l|l|l|l|l|l|l}
\hline \multirow{2}{*}{$\begin{array}{l}\text { RELAÇÃO } \\
\mathbf{a} / \mathbf{c}\end{array}$} & $\begin{array}{l}\text { ETA } \\
(\%)\end{array}$ & \multicolumn{2}{|l|}{ Quantidade $\left(\mathbf{k g} / \mathbf{m}^{\mathbf{3}}\right)$} & $\mathbf{C}\left(\mathbf{k g} / \mathbf{m}^{\mathbf{3}}\right)$ & $\begin{array}{l}\text { ABATIMENTO } \\
\mathbf{( m m )}\end{array}$ \\
\cline { 4 - 8 } & Areia & $\begin{array}{l}\text { Lodo } \\
\text { de ETA }\end{array}$ & Brita & & & \\
\hline 0,4 & 0 & 640,5 & 0 & 980,3 & 557 & 105 \\
\hline 0,5 & 0 & 761,3 & 0 & 978,8 & 435 & 105 \\
\hline 0,6 & 0 & 838,9 & 0 & 978,2 & 357 & 100 \\
\hline 0,5 & 2,5 & 742,1 & 17,36 & 976,5 & 434 & 95 \\
\hline 0,4 & 5 & 606,0 & 33,36 & 978,6 & 556 & 90 \\
\hline
\end{tabular}




\begin{tabular}{l|l|l|l|l|l|l}
\hline 0,5 & 5 & 720,4 & 39,06 & 976,5 & 434 & 90 \\
\hline 0,6 & 5 & 793,9 & 42,70 & 975,4 & 356 & 95 \\
\hline 0,5 & 7,5 & 701,5 & 56,29 & 974,3 & 433 & 90 \\
\hline 0,4 & 10 & 575,1 & 66,40 & 973,3 & 553 & 85 \\
\hline 0,5 & 10 & 682,6 & 77,80 & 972,0 & 432 & 80 \\
\hline 0,6 & 10 & 750,5 & 85,00 & 970,0 & 354 & 80 \\
\hline
\end{tabular}

Com base no que foi apresentado na Tabela 8, um teor de substituição de $5 \%$ de lodo de ETA por areia nas relações a/c 0,4, 0,5 e 0,6 apresentou redução de $34,4 \mathrm{~kg}, 40,9 \mathrm{~kg}$ e $45 \mathrm{~kg}$ por $\mathrm{m}^{3}$ de consumo de areia natural, respectivamente. Dessa forma, verificou-se uma redução média de aproximadamente 5,3\% de areia nos concretos, devendo-se considerar a relevância no que tange às questões de sustentabilidade. Esse aspecto possui importância significativa ao considerar-se que em Porto Alegre há uma retirada excessiva da areia do leito do Rio Jacuí, cujos dados recentes divulgados pela Fundação Estadual de Proteção Ambiental do RS (FEPAM) citam que durante o processo de dragagem algumas máquinas estão inclusive ultrapassando o limite imposto pelos órgãos ambientais, de deixar $1 \mathrm{~m}$ de areia no fundo do rio, acima da rocha sã.

Com base nos resultados experimentais obtidos foram construídos modelos matemáticos visando representar o comportamento dos concretos com lodo de ETA. Empregou-se a modelagem não linear para construção dos modelos, cujos mesmos foram considerados satisfatórios quando os valores do coeficiente de determinação $\left(\mathrm{R}^{2}\right)$ ficaram acima de $80 \%$. Tal procedimento já foi empregado antes em outros trabalhos [10,39], cujos resultados foram considerados satisfatórios.

\subsection{Ensaios realizados}

De acordo com o método prescrito pela NBR 5738 [40] foram moldados corpos de prova cilíndricos $(10 \times 20$ $\mathrm{cm}$ ) para a realização dos ensaios conforme apresentado na Tabela 9. Após 24 horas os corpos de prova foram desmoldados e mantidos em cura saturada, cujos mesmos foram retirados no momento da realização dos ensaios nas idades pré-determinadas.

Tabela 9: Ensaios adotados e as respectivas normas

\begin{tabular}{llll}
\hline & & \multicolumn{2}{l}{ NÚMERO DE COR- } \\
ENSAIO & NORMA TÉCNICA & POS DE PROVA & \\
\hline Absorção d'água por imersão & NBR 9778 [41] & 3 & 28 dias \\
Massa específica & NBR 9778 [41] & 3 & 28 dias \\
Porosidade & NBR 9778 [41] & 3 & 28 dias \\
$\begin{array}{l}\text { Resistência à compressão } \\
\text { Resistência à tração por compressão diame- } \\
\text { tral }\end{array}$ & NBR 5739 [42] & 3 & 7,28 e 91 dias \\
\hline
\end{tabular}

Uma das técnicas empregadas para planejar e analisar um experimento é a análise de variância (ANOVA - analysis of variance). Tal técnica de análise emprega a variância para fazer inferências sobre as médias populacionais. A análise de variância é um teste estatístico amplamente difundido entre os analistas, e visa fundamentalmente verificar se existe uma diferença significativa entre as médias e se os fatores exercem influência em alguma variável dependente. Desta forma, foram empregados três exemplares para a realização dos ensaios, visando realizar as análises estatísticas adequadas, a fim de gerar modelos que contemplem os parâmetros do processo que influenciam significativamente nas propriedades analisadas [44].

\section{RESULTADOS E DISCUSSÕES}

\subsection{Modelagem das propriedades avaliadas}

Com base nos resultados obtidos no programa experimental foram determinados modelos matemáticos que representem adequadamente as diversas propriedades de interesse, cujos mesmos encontram-se representados pelas Equações de 2 a 6.

$$
\mathrm{A}=1,8772+9,1069 \times \frac{\mathrm{a}}{\mathrm{c}}+0,3259 \times \mathrm{ETA}-0,3961 \times a / c \times E T A
$$




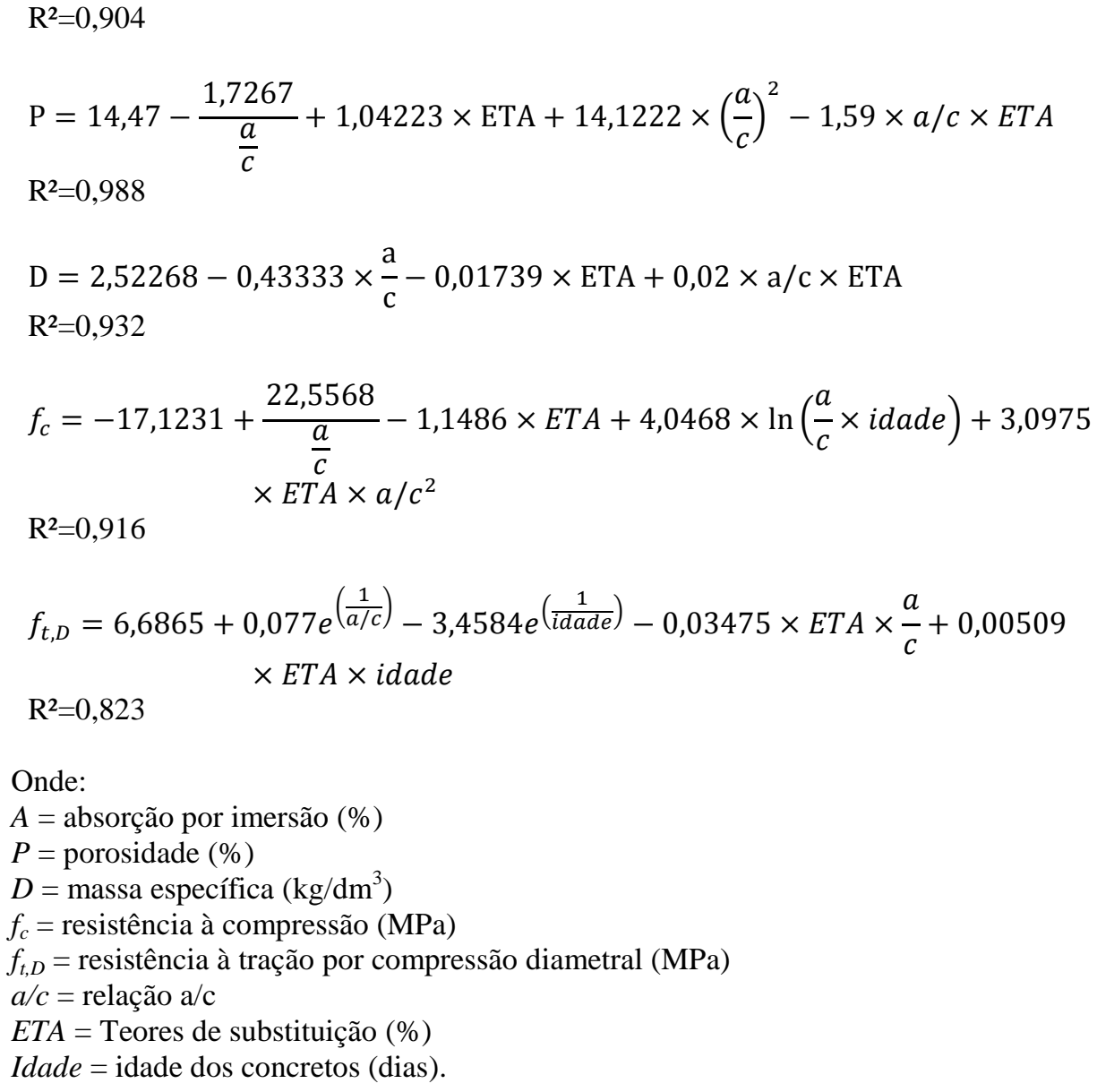

Onde:

$A=$ absorção por imersão (\%)

$P=$ porosidade $(\%)$

$D=$ massa específica $\left(\mathrm{kg} / \mathrm{dm}^{3}\right)$

$f_{c}=$ resistência à compressão $(\mathrm{MPa})$

$f_{t, D}=$ resistência à tração por compressão diametral $(\mathrm{MPa})$

$a / c=$ relação $\mathrm{a} / \mathrm{c}$

$E T A=$ Teores de substituição $(\%)$

Idade $=$ idade dos concretos (dias).

Os valores de $\mathrm{R}^{2}$ para todos os modelos foram maiores que 0,823 , indicando que os mesmos podem ser utilizados para explicar pelo menos $82,3 \%$ da variabilidade para a propriedade com menor aderência, cuja ANOVA (Tabela 10) mostrou que os modelos são estatisticamente significativos. Além disso, todos os coeficientes obtidos para os modelos individuais foram analisados, verificando-se que todos também mostraramse como significativos estatisticamente.

Tabela 10: ANOVA dos modelos ajustados

\begin{tabular}{|c|c|c|c|c|c|c|}
\hline VARIÁVEL & FONTE & SQ & GL & $M Q$ & TESTE $F$ & VALOR P \\
\hline \multirow{4}{*}{$A$} & Modelo & 1111,436 & 4,00 & 277,86 & 4027,50 & 0,000000 \\
\hline & Resíduo & 1,242 & 18,00 & 0,069 & & \\
\hline & Total & 1112,68 & 22,00 & & & \\
\hline & $\mathrm{R}^{2}=0,904$ & & & & & \\
\hline \multirow{4}{*}{$P$} & Modelo & 5527,70 & 5,00 & 1105,54 & 34023,96 & 0,000000 \\
\hline & Resíduo & 0,552 & 17,00 & 0,032 & & \\
\hline & Total & 5528,25 & 22,00 & & & \\
\hline & $\mathrm{R}^{2}=0,988$ & & & & & \\
\hline \multirow{4}{*}{$D$} & Modelo & 113,30 & 4,00 & 28,33 & 219261,3 & 0,000000 \\
\hline & Resíduo & 0,0023 & 18,00 & 0,00013 & & \\
\hline & Total & 113,301 & 22,00 & & & \\
\hline & $\mathrm{R}^{2}=0,932$ & & & & & \\
\hline \multirow{4}{*}{$f_{c}$} & Modelo & 72982,92 & 5,00 & 14596,58 & 3409,34 & 0,000000 \\
\hline & Resíduo & 201,22 & 47,00 & 4,28 & & \\
\hline & Total & 73184,14 & 52,00 & & & \\
\hline & $\mathrm{R}^{2=}=0,916$ & & & & & \\
\hline \multirow{4}{*}{$f_{t, D}$} & Modelo & 592,46 & 5,00 & 118,49 & 4023,29 & 0,000000 \\
\hline & Resíduo & 1,17 & 40,00 & 0,029 & & \\
\hline & Total & 593,644 & 45,00 & & & \\
\hline & $\mathrm{R}^{2}=0,823$ & & & & & \\
\hline
\end{tabular}

$\mathrm{SQ}=$ soma quadrática, $\mathrm{GL}=$ graus de liberdade, $\mathrm{MQ}=$ Média quadrática 
Na Figura 8 estão apresentados os comportamentos dos resíduos para $\mathrm{f}_{\mathrm{c}}$ e $\mathrm{f}_{\mathrm{t}, \mathrm{D}}$, mostrando que os mesmos encontram-se dispersos de forma aleatória, corroborando a aderência dos modelos obtidos.

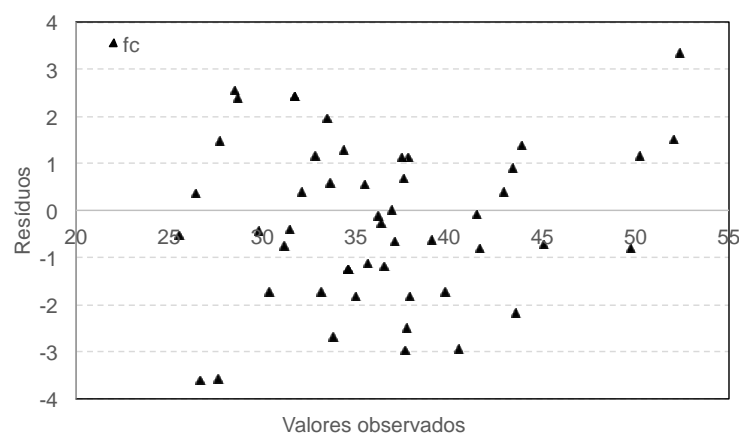

(a)

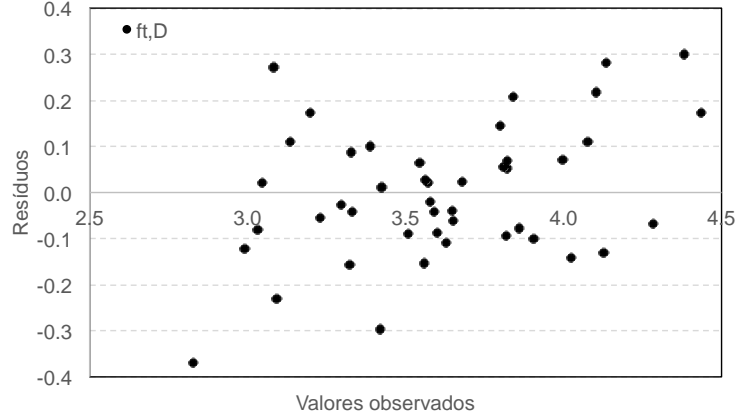

(b)

Figura 8: Valores observados x resíduos a) Resistência à compressão $\left(f_{c}\right)$ b) Resistência à tração por compressão diame$\operatorname{tral}\left(f_{t, D}\right)$

\subsection{Propriedades físicas dos concretos}

A partir dessa seção, para todas as propriedades avaliadas (tanto físicas quanto mecânicas) os resultados obtidos através dos modelos encontram-se representados por linhas, cujos valores médios dos dados experimentais são representados pelos símbolos. Além disso, estão apresentados os intervalos dos desvios-padrão para cada ponto experimental (símbolo).

Na Figura 9 está apresentado o comportamento da porosidade e da absorção d'água dos concretos com os teores de substituição de areia por lodo de ETA.

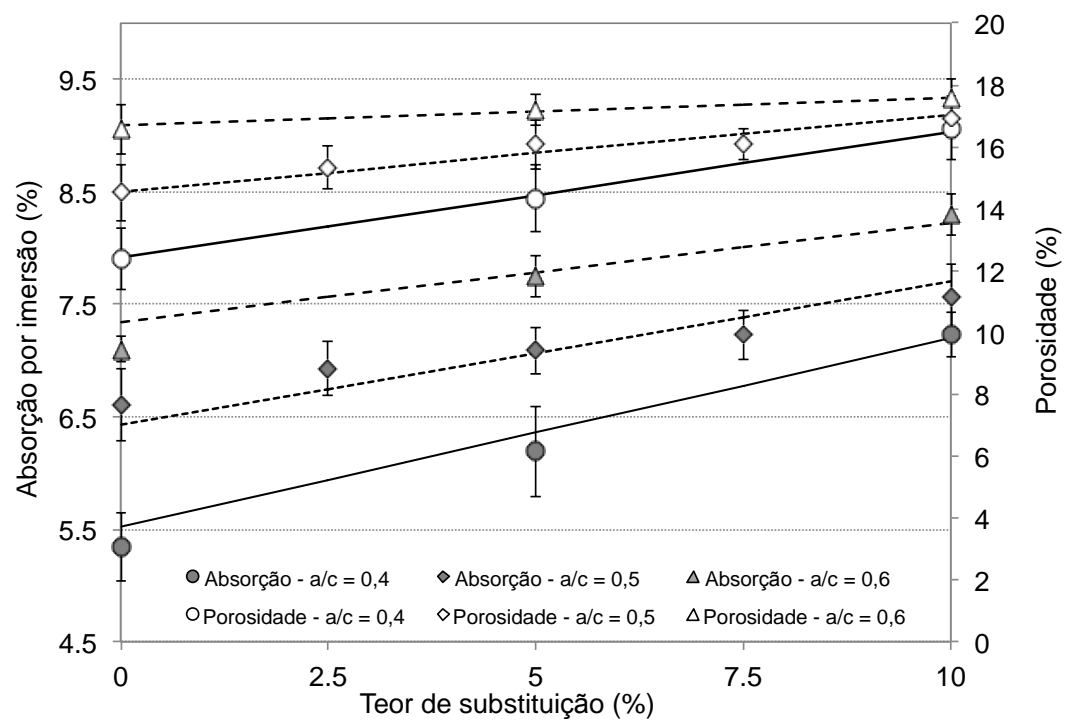

Figura 9: Efeito do teor de substituição na porosidade e na absorção d'água dos concretos aos 28 dias

Com o aumento da substituição de lodo de ETA verificou-se um incremento tanto da porosidade quanto da absorção d'água dos concretos. Ao se comparar os concretos de referência com os exemplares com $10 \%$ de lodo de ETA pode-se verificar uma tendência semelhante. Para a relação a/c igual a 0,40 observou-se um aumento de aproximadamente $30 \%$ entre o concreto de referência e o concreto com maior teor de substituição. Já para concretos com relação a/c = 0,60 tem-se que o aumento da absorção d'água foi menor (13,5\%). Para o caso da porosidade tem-se que o aumento foi igual a 32,7\% e 5,3\% considerando as relações a/c iguais a 0,4 e 0,6, respectivamente. Pode-se verificar que o efeito da incorporação de lodo de ETA é mais evidente nos concretos com menores relações a/c, enquanto que para a maior relação a/c a quantidade de lodo de ETA incorporada não afetou a porosidade e a absorção d'água na mesma proporção. 
SOUZA [45] investigou o efeito da substituição de 5 teores de lodo de ETA (1\%, 2\%, 3\%, 4\% e 5\%) em concretos com resistências aos 28 dias entre 24,7 MPa a $29 \mathrm{MPa}$, cujos valores de absorção d'água encontrados variaram entre $3,97 \%$ e $5,15 \%$, sendo menores que o concreto de referência $(5,4 \%)$. Segundo o autor, a durabilidade - medida indiretamente pela absorção d'água - não foi afetada pela adição do lodo de ETA, todavia não foi apresentada uma análise estatística a fim de validar tal afirmação. Já RAMIREZ [24] verificou que com a adição do lodo de ETA calcinado em diversos teores de substituição (5\%, 10\% e 20\%) ocorreu um aumento da absorção d'água por capilaridade nos concretos para uma mesma relação a/c $(0,55)$, cujos resultados mostraram-se estatisticamente significativos de acordo com a análise de variância realizada. Resultados similares foram encontrados por TAFAREL et al. [36], cujos autores encontraram um incremento de $12 \%$ e $32 \%$ na absorção d'água por imersão para teores de $5 \%$ e $10 \%$ de incorporação de lodo de ETA, respectivamente.

De uma forma geral, a tendência de aumento da absorção d'água dos concretos com lodo de ETA é esperada, principalmente em função da elevada absorção do material e da sua microestrutura porosa. De acordo com AHMAD et al. [46], essa é uma das grandes desvantagens do material, mas que pode ser adequadamente ajustada durante o procedimento de dosagem dos concretos em função das exigências requeridas para situações específicas. aos 28 dias.

$\mathrm{Na}$ Figura 10 pode-se verificar o comportamento da massa específica dos concretos com lodo de ETA

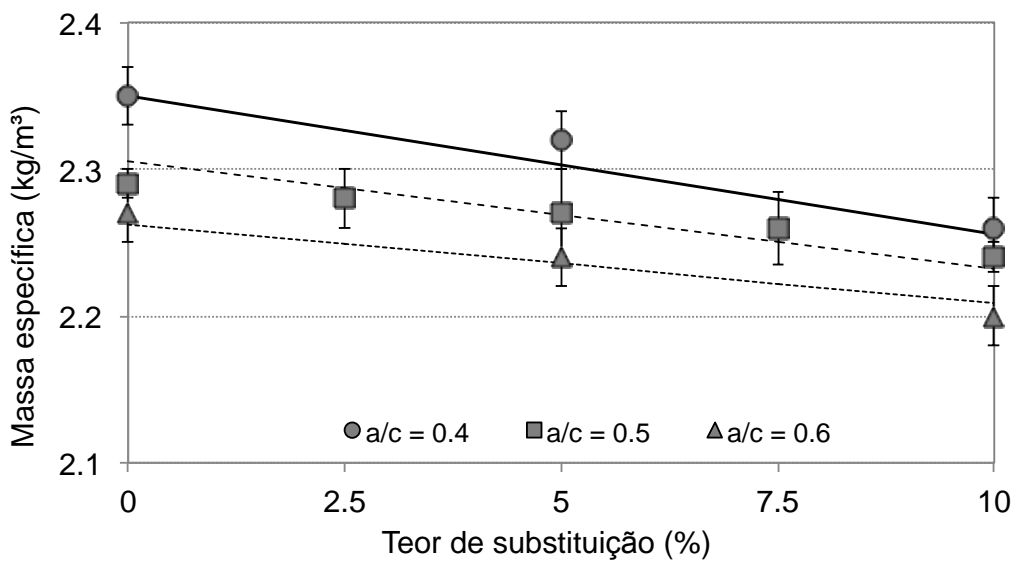

Figura 10: Efeito do teor de ETA na massa específica dos concretos (28 dias)

Assim como relatado em outros trabalhos [24, 30] observou-se que a incorporação de lodo de ETA causou uma diminuição da massa específica dos concretos. Isso deve-se à menor massa específica do lodo de ETA [47], conforme apresentado na Tabela 1, pois durante o processo de calcinação do resíduo há a geração de produtos voláteis que formam pequenas cavidades dentro da partícula do material [30].

\subsection{Propriedades mecânicas}

Baseado nos resultados obtidos dos modelos de regressão e na média e desvios-padrão dos dados experimentais foi possível verificar o comportamento mecânico dos concretos com lodo de ETA. Os resultados do ensaio de resistência à compressão estão apresentados na Figura 11. 


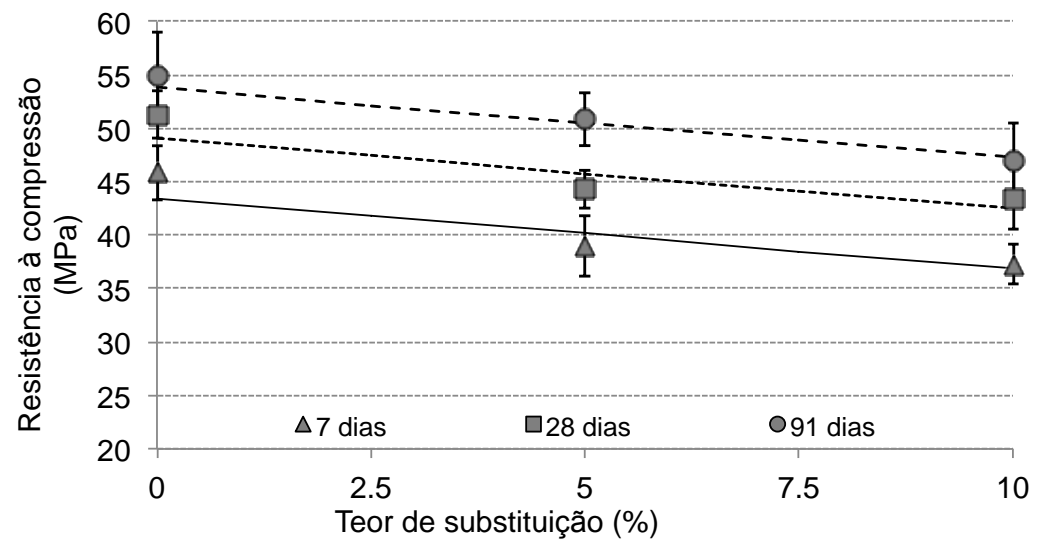

(a)

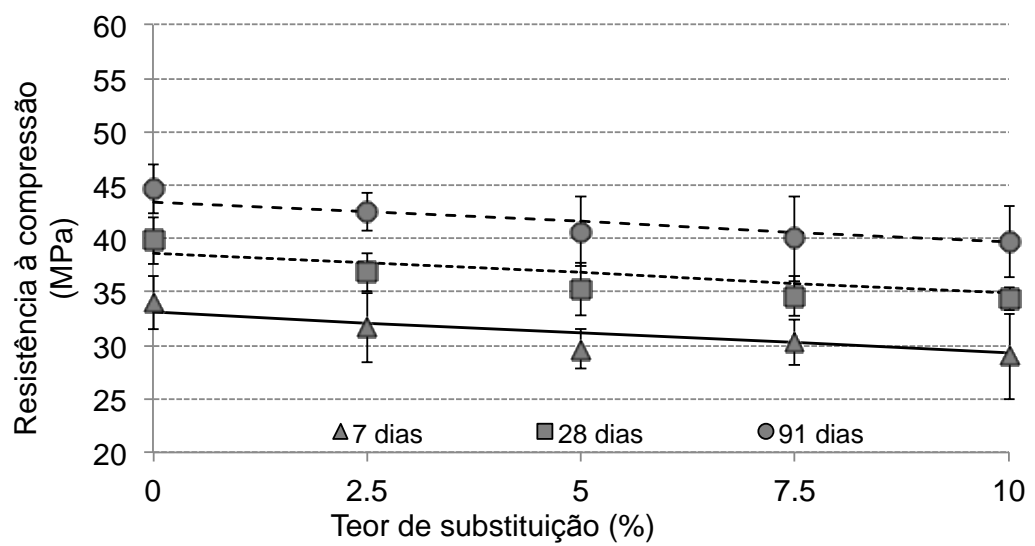

(b)

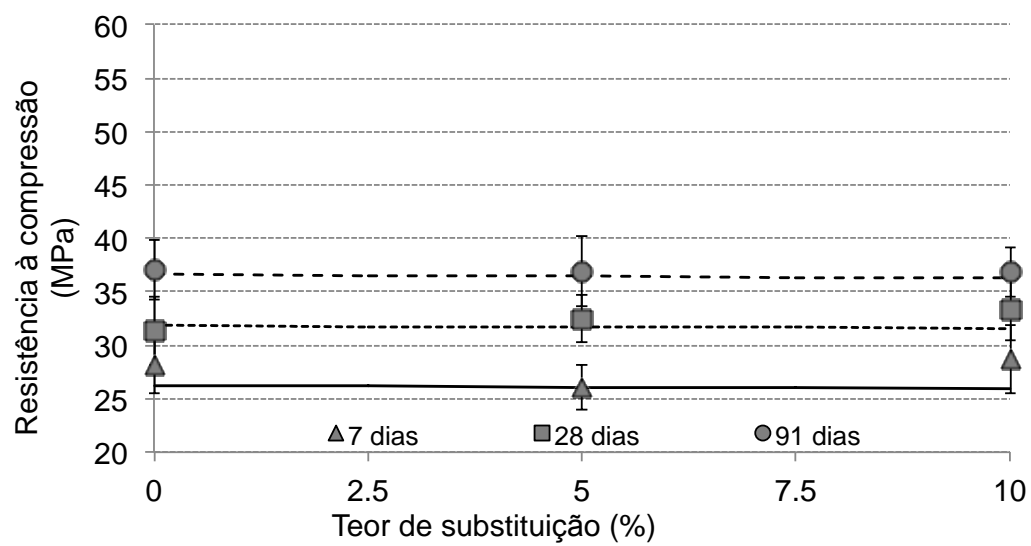

(c)

Figura 11: Resistências à compressão dos concretos com lodo de ETA: a/c $=0,4(a) ; a / c=0,5(b) ; a / c=0,6(c)$

De forma geral pode-se observar que o efeito do acréscimo do teor de lodo de ETA na resistência à compressão é mais evidente para concretos com menores relações a/c. Considerando a idade de 91 dias, os concretos com relação a/c $=0,4$ apresentaram uma queda de resistência igual a 12,1\% (correspondente a uma minimização da resistência igual a $6,53 \mathrm{MPa}$ ) entre os concretos de referência e com $10 \%$ de lodo de ETA. Já para as relações a/c igual a 0,5 e 0,6 os decréscimos de resistência foram iguais a 8,6\% e $0,9 \%$ para a mesma idade (91 dias) e níveis de substituição (referência e 10\%).

Resultados similares foram encontrados por Kaosol [48], cujo autor verificou a variação de resistência à compressão de blocos vazados de concreto com lodo de ETA. Os resultados dos ensaios mostraram que a incorporação de lodo de ETA entre 10 e $20 \%$ atingiam o valor mínimo (5 MPa) estabelecido pela normalização da Tailândia para utilização em blocos estruturais. Yaguie, et al. [22] investigaram a influência do teor de lodo de ETA na resistência à compressão de concretos, cujos autores verificaram que teores de substituição 
iguais a 2,5\%,5\% e $10 \%$ acarretaram em reduções de aproximadamente $31,5 \%, 44,4 \%$ e 53,7\% em relação ao concreto de referência com cura úmida, respectivamente. Hoppen et al. [12] verificaram uma tendência de redução semelhante, encontrando decréscimos de resistência em torno de $14 \%$ para um teor de substituição de $4 \%$ de lodo aos 28 dias. TAFAREL et al. [36] observaram uma redução de $11,4 \%$ e $29,3 \%$ na $\mathrm{f}_{\mathrm{c}}$ com a adição de $5 \%$ e $10 \%$ de lodo de ETA em concretos aos 28 dias, cujos resultados apresentaram diferenças estatisticamente significativas.

Todavia, outras pesquisas mostram um discreto aumento da resistência à compressão com a incorporação do lodo de ETA. Ao estudar a influência de diversos teores de substituição de areia (5\%, 10\% e 20\%) por lodo de ETA, RAMIREZ [24] verificou que houve uma pequena variação das resistências dos concretos com relação a/c igual a 0,55 para as idades de 7, 28, 60 e 90 dias. Os resultados mostraram que aos 90 dias os concretos com lodo de ETA apresentaram resistências maiores que os exemplares de referência. Tendência similar foi encontrada por SOUZA [49], que verificou um aumento de resistência de concretos com teores de substituição de $1 \%$ a $5 \%$ de agregado miúdo por lodo de ETA aos 28 dias. Segundo o autor, aos 28 dias o concreto com $2 \%$ de substituição apresentou uma resistência $27 \%$ superior ao concreto de referência. Figura 12 .

Os comportamento da resistência à tração por compressão diametral $\left(\mathrm{f}_{t, D}\right)$ encontra-se apresentado na

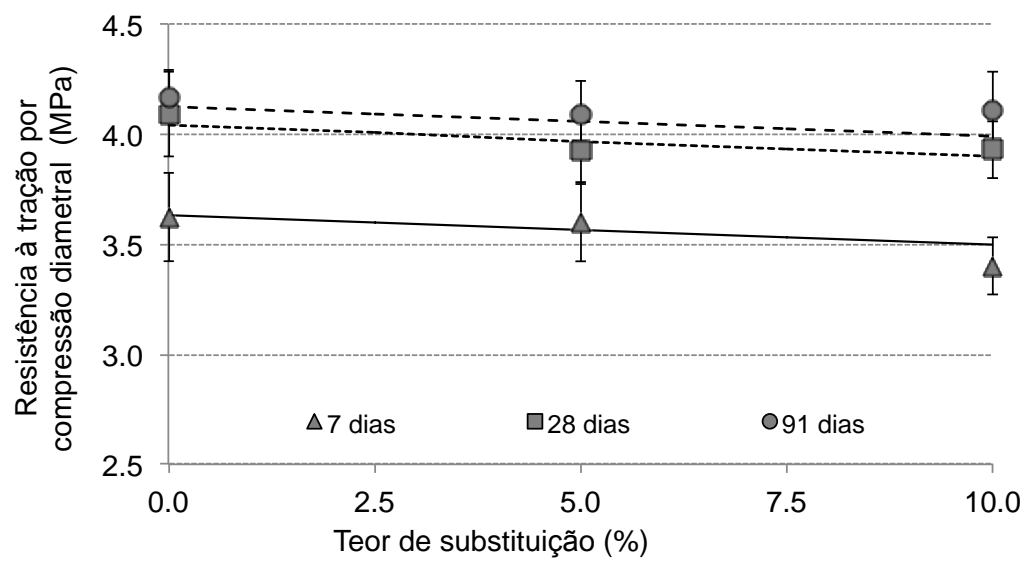

(a)

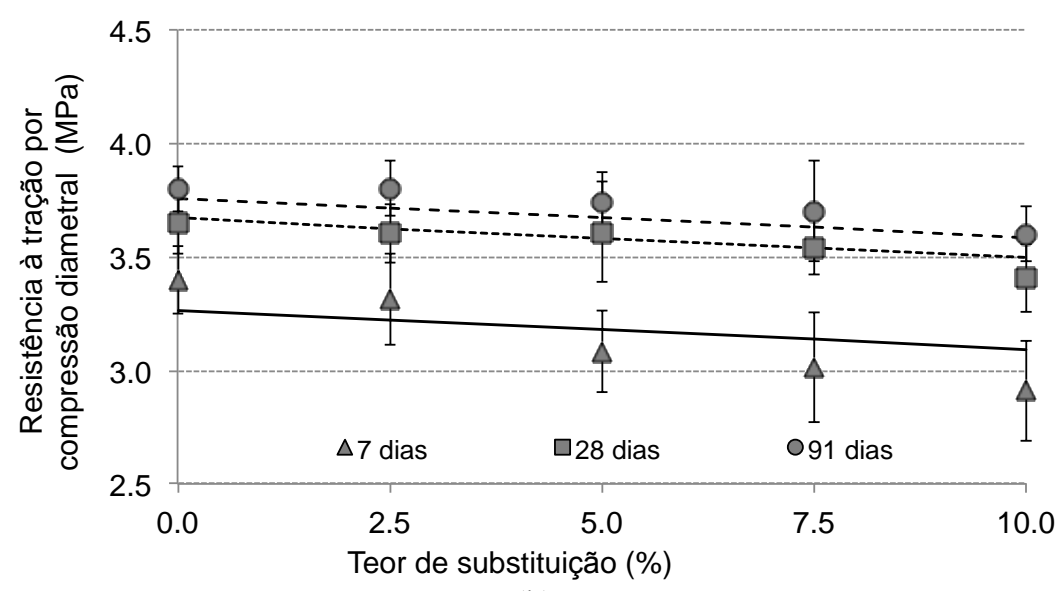

(b) 


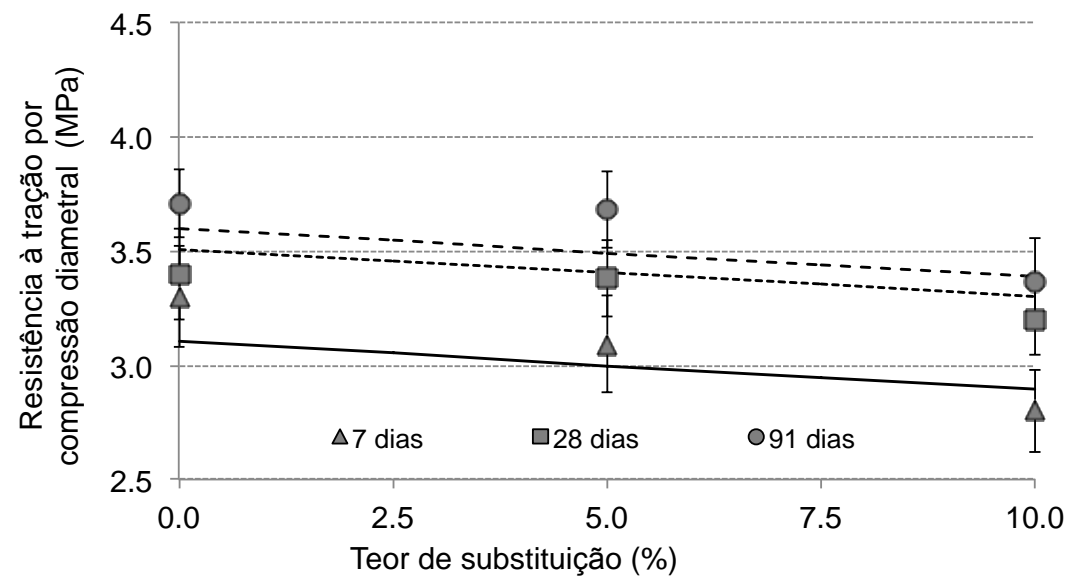

(c)

Figura 12: Resistências à tração por compressão diametral nos concretos com lodo de ETA: a/c = 0,4 (a); a/c = 0,5 (b); $\mathrm{a} / \mathrm{c}=0,6(\mathrm{c})$

A incorporação de lodo de ETA tem um efeito mais significativo do que na resistência à compressão, bem como verifica-se que os valores de desvio-padrão foram mais elevados que aqueles encontrados para $f_{c}$. A minimização das resistências considerando uma substituição de $10 \%$ em relação ao concreto de referência aos 91 dias foi igual a 20,7\%,10,1\% e 12,4\% para as relações a/c 0,4, 0,5 e 0,6, respectivamente. Em relação ao comportamento de tal propriedade em materiais compósitos com lodo de ETA não há um consenso na literatura. Ao investigar o efeito da adição do lodo calcinado ao concreto em vários teores $(5 \%, 7 \%, 10 \%$ e $20 \%$ ) para uma relação a/c fixa e igual 0,55, RAMIREZ et al. [35] verificaram um ligeiro aumento nos valores de $\mathrm{f}_{t, \mathrm{D}}$ aos 28 dias. Melhores resultados foram obtidos com uma adição de $10 \%$ de lodo de ETA, que acarretou em um incremento de $13,5 \%$ em tal propriedade. Tendência semelhante foi encontrada por TAFAREL et al. [36], cujos autores constataram que a adição de 5\% e 10\% de lodo acarretou um aumento de $11 \%$ e uma diminuição de $13 \%$ em relação ao concreto de referência, respectivamente. Já MONTEIRO et al. [20], ao incorporar o lodo de ETA em materiais cerâmicos em teores de 3\%, 5\% e 10\%, verificaram uma diminuição da resistência à tração, independentemente da temperatura de calcinação do material $\left(700^{\circ} \mathrm{C}, 900^{\circ} \mathrm{C} \mathrm{e}\right.$ $1100^{\circ} \mathrm{C}$ ). Resultados similares foram encontrados por PAIXÃO et al. [50] ao investigar o efeito da adição do lodo de ETA em cerâmicas, cujos autores constataram uma redução de $50 \%$ da resistência à flexão em relação às amostras de referência.

Deve-se considerar que a distribuição granulométrica da areia e do lodo de ETA são ligeiramente diferentes (Figura 6). Tal fato pode ser uma vantagem para os concretos com lodo de ETA devido ao efeito de empacotamento granulométrico, no qual as partículas pequenas podem preencher os vazios do concreto, aumentando discretamente a resistência à tração por compressão diametral dos concretos com baixas relações a/c, conforme pode ser observado na Figura 12. NEVILLE [51] cita que os agregados miúdos também têm uma influência na resistência à tração por compressão diametral dos concretos, bem como a distribuição granulométrica dos mesmos. Além disso, tem-se a elevada variabilidade associada com os resultados de tal ensaio, que está diretamente relacionado com as características tanto da matriz quanto da zona de transição entre o agregado e a pasta. Considerando que há a inclusão de mais uma fase (agregado de lodo de ETA) em relação aos concretos de referência, há a introdução de mais defeitos na matriz do compósito, aumentando a variabilidade da resistência das amostras.

MEHTA e MONTEIRO [7] afirmam que existe uma proporcionalidade na relação entre a resistência à compressão e resistência à tração por compressão diametral, cujas análises foram realizadas visando verificar se tal comportamento era observado nos concretos com lodo de ETA. Na Figura 13 está apresentada a relação entre as resistências à compressão e a tração por compressão diametral para os concretos de referência e com $10 \%$ de lodo de ETA aos 28 dias, na qual pode-se verificar a proporcionalidade existente entre as propriedades, independentemente da relação a/c empregada para a fabricação dos concretos. 


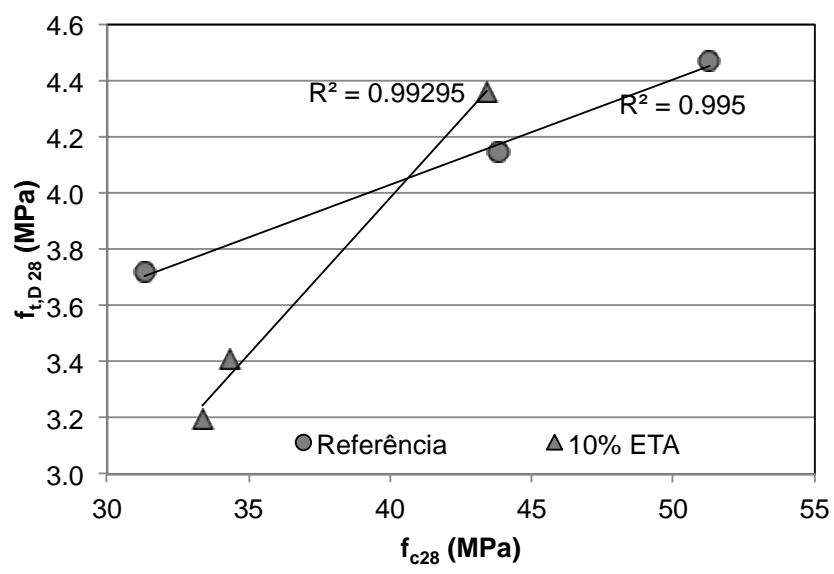

Figura 13: Relação entre $\mathrm{f}_{\mathrm{c}}$ e $\mathrm{f}_{\mathrm{t}, \mathrm{D}}$ aos 28 dias

De acordo com MEHTA e MONTEIRO [7] para concretos considerados de baixa resistência a relação entre a resistência à compressão e à tração varia entre 10 e $11 \%$, podendo atingir valores entre 8 a $9 \%$ e $7 \%$ para concretos de média e alta resistência, respectivamente. De acordo com a Figura 13 é possível observar que à medida em que a resistência a compressão aumenta, a resistência a tração por compressão diametral também aumenta. Desta forma, pode-se observar na Tabela 11 o atendimento da relação entre as resistências à compressão e à tração dos concretos investigados. Vale salientar que a determinação de tais valores levou em consideração as médias das resistências obtidas através dos ensaios realizados. Os resultados observados com a relação entre as resistências com os concretos com lodo de ETA atenderam os percentuais próximos ao descritos pelos autores.

Tabela 11: Relação $(\%)$ entre as resistências à compressão $\left(\mathrm{f}_{\mathrm{c}}\right)$ e à tração $\left(\mathrm{f}_{\mathrm{t}, \mathrm{D}}\right)$ aos 28 dias

\begin{tabular}{l|r|r|r}
\hline $\begin{array}{l}\text { RELAÇÃO } \\
\text { a/c }\end{array}$ & \multicolumn{3}{|l}{ Teor de lodo de ETA } \\
\hline & \multicolumn{1}{|l|}{$\mathbf{0} \%$} & $\mathbf{5} \%$ & $\mathbf{1 0} \%$ \\
\hline 0,4 & $9 \%$ & $9 \%$ & $10 \%$ \\
\hline 0,5 & $9 \%$ & $11 \%$ & $10 \%$ \\
\hline 0,6 & $12 \%$ & $11 \%$ & $10 \%$ \\
\hline
\end{tabular}

Segundo NEVILLE [51], para corpos de prova cilíndricos o valor médio da resistência à tração por compressão diametral pode ser estimado pela Equação 6, cujos resultados encontram-se apresentados na Figura 14.

$$
f_{t, D}=0,3 \times \sqrt[3]{f_{c}}
$$

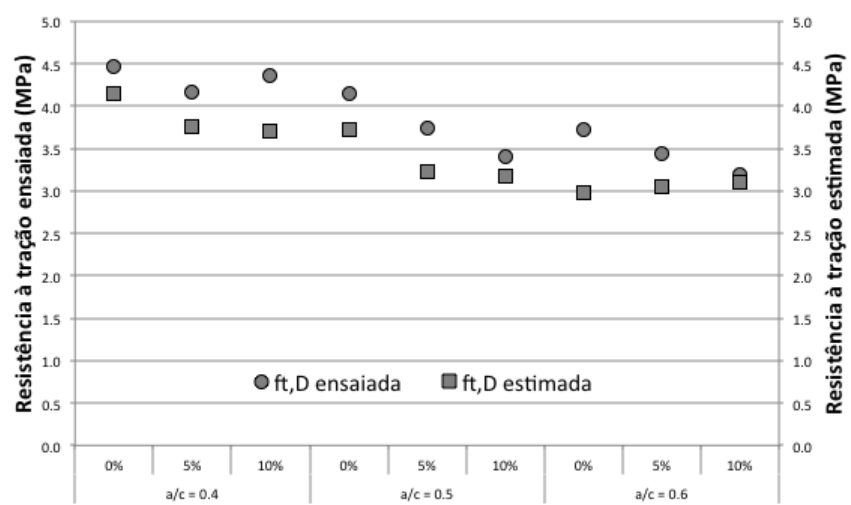

Figura 14: Relação entre a resistência à tração ensaiada e a estimada com base na resistência à compressão aos 28 dias 
Assim como observado por RAMIREZ [24], os valores de resistência à tração determinados através da resistência à compressão aos 28 dias do concreto apresentam pequenas diferenças, ratificando a relação existente entre tais propriedades para concretos com os teores de substituição de agregado miúdo por lodo de ETA. Além disso, deve-se levar em consideração que as relações encontradas estão diretamente relacionadas com a peculiaridade de cada lodo de ETA e do tipo de cimento empregado para a fabricação dos concretos.

\section{CONCLUSÕES}

Tendo em vista a necessidade de sustentabilidade na indústria da construção civil em função do consumo de grande parte dos recursos naturais, este estudo vem ao encontro da busca de resíduos que tem grande potencialidade como matéria prima para a construção civil. Com base nos resultados obtidos as seguintes considerações podem ser destacadas:

- No que se refere à caracterização físico-química do lodo de ETA verificou-se que as principais propriedades analisadas apresentam valores similares aos encontrados em outros trabalhos publicados, mostrando que o lodo de ETA empregado tem potencial para uso na Construção Civil;

- Verificou-se que tanto a relação a/c quanto o teor de substituição apresentaram influência significativa nas propriedades físico-mecânicas dos concretos analisados;

- Em relação às propriedades físicas verificou-se que o emprego de lodo de ETA em concretos diminuiu a massa específica e aumentou tanto a porosidade quanto a absorção dos compósitos, em função principalmente da elevada absorção d'água do material;

- A diminuição dos valores de resistência à compressão foi mais evidente para os concretos com menores relações a/c. Para concretos de menores resistências a incorporação de lodo de ETA não teve influência em tal propriedade, evidenciando a potencialidade de substituição da areia pelo lodo calcinado.

- $\quad$ Com base neste estudo, verificou-se que a substituição de areia por 5\% de lodo de ETA acarretou uma diminuição de 5,3\% para cada $\mathrm{m}^{3}$ de consumo de material não renovável por lodo de ETA.

Sendo assim, verifica-se que os concretos com lodo de ETA com baixos teores de substituição, se dosados de forma adequada, podem ser empregados em elementos estruturais. Todavia, há a necessidade a realização de ensaios específicos de durabilidade (carbonatação, penetração de cloretos, ataques químicos, entre outros) para ratificar a possibilidade de emprego em maior escala.

\section{BIBLIOGRAFIA}

[1] HÄFLIGER, I.-F., JOHN, V., PASSER, A., et al., "Buildings environmental impacts' sensitivity related to LCA modelling choices of construction materials", Journal of Cleaner Production, v. 156, n. pp. 805-816, 2017.

[2] SMOL, M., KULCZYCKA, J., HENCLIK, A., et al., "The possible use of sewage sludge ash (SSA) in the construction industry as a way towards a circular economy", Journal of Cleaner Production, v. 95, n. pp. 45-54, 2015.

[3] AJAYI, S.O., OYEDELE, L.O., AKINADE, O.O., et al., "Attributes of design for construction waste minimization: A case study of waste-to-energy project", Renewable and Sustainable Energy Reviews, v. 73, n. pp. 1333-1341, 2017.

[4] MILLER, S.A., HORVATH, A., MONTEIRO, P.J.M., "Impacts of booming concrete production on water resources worldwide”, Nature Sustainability, v. 1, n. 1, pp. 69-76, 2018.

[5] GONZÁLEZ-KUNZ, R.N., PINEDA, P., BRAS, A., et al., "Plant biomass ashes in cement-based building materials. Feasibility as eco-efficient structural mortars and grouts", Sustainable Cities and Society, v. 31, n. pp. 151-172, 2017.

[6] SCHNEIDER, M., ROMER, M., TSCHUDIN, M., et al., "Sustainable cement production-present and future", Cement and Concrete Research,v. 41, n. 7, pp. 642-650, 2011.

[7] MEHTA, P.K., MONTEIRO, P.J.M., Concrete: Microstructure, Properties, and Materials, 3th ed., McGraw-Hill2006.

[8] BAEZA-BROTONS, F., GARCÉS, P., PAYÁ, J., SAVAL, J.M., "Portland cement systems with addition of sewage sludge ash. Application in concretes for the manufacture of blocks", Journal of Cleaner Production, 
v. 82, n. pp. 112-124, 2014.

[9] SILVA, S.R., ANDRADE, J.J.O., "Investigation of mechanical properties and carbonation of concretes with construction and demolition waste and fly ash", Construction and Building Materials, v. 153, n. pp. 704-715, 2017.

[10] ANDRADE, J.J.O., POSSAN, E., SQUIAVON, J.Z., et al., "Evaluation of mechanical properties and carbonation of mortars produced with construction and demolition waste", Construction and Building Materials, v. 161, n. pp. 70-83, 2018.

[11] TANTAWY, M.A., "Characterization and pozzolanic properties of calcined alum sludge", Materials Research Bulletin, v. 61, n. pp. 415-421, 2015.

[12] HOPPEN, C., PORTELLA, K.F., JOUKOSKI, A., et al., "Co-disposição de lodo centrifugado de estação de tratamento de água (eta) em matriz de concreto: método alternativo de preservação ambiental”, Cerâmica,v. 51, pp. 85-95, 2005.

[13] AHMAD, T., AHMAD, K., ALAM, M., "Characterization of Water Treatment Plant's Sludge and its Safe Disposal Options”, Procedia Environmental Sciences, v. 35, n. pp. 950-955, 2016.

[14] TEIXEIRA, S.R., SANTOS, G.T.A., SOUZA, A.E., et al., "The effect of incorporation of a Brazilian water treatment plant sludge on the properties of ceramic materials", Applied Clay Science,v. 53, n. 4, pp. $561-565,2011$.

[15] ASSOCIAÇÃO BRASILEIRA DE NORMAS TÉCNICAS, NBR 10004, Resíduos sólidos - Classificação, Rio de Janeiro, 2004.

[16] GASTALDINI, A.L.G., HENGEN, M.F., GASTALDINI, M.C.C., et al., "The use of water treatment plant sludge ash as a mineral addition”, Construction and building materials, v. 94, n. pp. 513-520, 2015.

[17] DI BERNARDO, L., DANTAS, A.D.B., Métodos e técnicas de tratamento de água, 2 ed., São Carlos, 2005.

[18] WANG, Q., WEI, W., GONG, Y., et al., "Technologies for reducing sludge production in wastewater treatment plants: State of the art”, Science of The Total Environment, v. 587, n. pp. 510-521, 2017.

[19] EL-DIDAMONY, H., KHALIL, K.A., HEIKAL, M., "Physico-chemical and surface characteristics of some granulated slag-fired drinking water sludge composite cement pastes", HBRC Journal, v. 10, n. 1, pp. 73-81, 2014.

[20] MONTEIRO, S.N., ALEXANDRE, J., MARGEM, J.I., et al., "Incorporation of sludge waste from water treatment plant into red ceramic", Construction and Building Materials, v. 22, n. 6, pp. 1281-1287, 2008.

[21] FRÍAS, M., VIGIL DE LA VILLA, R., DE SOTO, I., et al., "Influence of activated drinking-water treatment waste on binary cement-based composite behavior: Characterization and properties", Composites Part B: Engineering, v. 60, n. pp. 14-20, 2014.

[22] YAGÜE, A., VALLS, S., VÁZQUEZ, E., et al., "Durability of concrete with addition of dry sludge from waste water treatment plants", Cement and Concrete Research, v. 35, n. pp. 1064-1073, 2005.

[23] JAMSHIDI, M., JAMSHIDI, A., MEHRDADI, N., et al., "Mechanical performance and capillary water absorption of sewage sludge ash concrete (SSAC)", International Journal of Sustainable Engineering, v. 5, n. 3, pp. 228-234, 2011.

[24] RAMIREZ, K.G., Viabilidade do aproveitamento de resíduo de estação de tratamento de água (eta) na confecção de concretos, Dissertação de M.Sc., UTFPR, medianeira, 2015.

[25] SALES, A., CORDEIRO, J.S., PALIARI, J.C., et al., "Utilização de resíduos gerados em estações de tratamento de água em argamassas e concretos de Cimento Portland”, In: Congresso Brasileiro de Engenharia e Ciência dos Materiais, Natal, pp. 1560-1567, 2002.

[26] ASSOCIAÇÃO BRASILEIRA DE NORMAS TÉCNICAS, NBR 5733, Cimento Portland de alta resistência inicial - especificação, Rio de Janeiro, 1991.

[27] KIZINIEVIČ, O., ŽURAUSKIENĖ, R., KIZINIEVIČ, V., et al., "Utilisation of sludge waste from water treatment for ceramic products”, Construction and Building Materials, v. 41, n. pp. 464-473, 2013.

[28] GODOY, L.G.G., Incorporação de lodo de estação de tratamento de água (eta) calcinado em cimento composto e pozolânico, Dissertação de M.Sc., Fundação Universidade Regional de Blumenau, Blumenau, 2018.

[29] ASSOCIAÇÃO BRASILEIRA DE NORMAS TÉCNICAS, NBR 15894-1, metacaulim para uso com Cimento Portland em concreto, argamassa e pasta - parte 1: requisitos, Rio de Janeiro, 2010. 
[30] VALLS, S., YAGÜE, A., VÁZQUEZ, E., et al., "Physical and mechanical properties of concrete with added dry sludge from a sewage treatment plant”, Cement and Concrete Research, v. 34, n. pp. 2203-2208, 2004.

[31] RODRÍGUEZ, N.H., RAMÍREZ, S.M., VARELA, M.T.B., et al., "Re-use of drinking water treatment plant (DWTP) sludge: Characterization and technological behaviour of cement mortars with atomized sludge additions", Cement and Concrete Research, v. 40, n. 5, pp. 778-786, 2010.

[32] ASSOCIAÇÃO BRASILEIRA DE NORMAS TÉCNICAS, NBR 15900-1, água para amassamento do concreto - parte 1: requisitos, Rio de Janeiro, 2009.

[33] CONSELHO NACIONAL DO MEIO AMBIENTE, CONAMA 357, Resolução 357, Rio de Janeiro, 2005.

[34] ASSOCIAÇÃO BRASILEIRA DE NORMAS TÉCNICAS, NBR 10005, Procedimento para obtenção de extrato lixiviado de resíduos sólidos, Rio de Janeiro, 2004.

[35] RAMIREZ, K.G., POSSAN, E., DEZEN, B.G., Influência da adição de lodo de eta in natura e calcinado na produção de concreto, In: 57 O Congresso Brasileiro do Concreto, IBRACON, Bonito, 2015.

[36] TAFAREL, N.F., MACIOSKI, G., CARVALHO, K.Q., et al., "Avaliação das propriedades do concreto devido à incorporação de lodo de estação de tratamento de água", Matéria (R.J),v. 21, n. 4, pp. 974-986, 2016.

[37] HELENE, P.R.L., TERZIAN, P., Manual de dosagem e controle do concreto, PINI, São Paulo, 1992.

[38] LEITE, M.B., Avaliação de propriedades mecânicas de concretos produzidos com agregados reciclados de resíduos de construção e demolição, Tese de D.Sc., UFRGS, Porto Alegre, RS, Brasil, 2001.

[39] CABRAL, A.E.B., SCHALCH, V., MOLIN, D.C.C.D., et al., "Mechanical properties modeling of recycled aggregate concrete", Construction and Building Materials, v. 24, n. 4, pp. 421-430, 2010.

[40] ASSOCIAÇÃO BRASILEIRA DE NORMAS TÉCNICAS, NBR 5738, Concreto - procedimento para moldagem e cura de corpos-de-prova, Rio de Janeiro, 2015.

[41] ASSOCIAÇÃO BRASILEIRA DE NORMAS TÉCNICAS, NBR 9778, Argamassa e concreto endurecidos - determinação da absorção de água, índice de vazios e massa específica, Rio de Janeiro, 2009.

[42] ASSOCIAÇÃO BRASILEIRA DE NORMAS TÉCNICAS, NBR 5739, Concreto - ensaio de compressão em corpos-de-prova cilíndricos, Rio de Janeiro, 2007.

[43] ASSOCIAÇÃO BRASILEIRA DE NORMAS TÉCNICAS, NBR 7222, Concreto e argamassa - determinação da resistência à tração por compressão diametral de corpos-de-prova cilíndricos, Rio de Janeiro, 2011.

[44] MONTGOMERY, D.C., Design and Analysis of Experiments, 5th ed., John Wiley \& Sons, New York, 2001.

[45] SOUZA, F.R.D., Estudo da eco-eficiência de argamassas e concretos reciclados com resíduos de estações de tratamento de água e de construções e demolições, Dissertação de M.Sc, Universidade Federal de São Carlos, São Carlos, 2006.

[46] AHMAD, T., AHMAD, K., ALAM, M., "Sustainable management of water treatment sludge through 3'R' concept", Journal of Cleaner Production, v. 124, n. pp. 1-13, 2016.

[47] HOPPEN, C., PORTELLA, K.F., JOUKOSKI, A., et al., "Uso de lodo de estação de tratamento de água centrifugado em matriz de concreto de cimento portland para reduzir o impacto ambiental", Química Nova,v. 29, n. 1, pp. 79-84, 2006.

[48] KAOSOL, T., "Reuse water treatment sludge for hollow concrete block manufacture", Energy Research Journal, v. 1, n. 2, pp. 131-134, 2010.

[49] SOUZA, F.R., Estudo da eco-eficiência de argamassas e concretos reciclados com resíduos de estações de tratamento de água e de construções e demolições, Dissertação de M.Sc., UFSCAR, São Carlos, 2006.

[50] PAIXÃO, L.C.C., YOSHIMURA, H.N., ESPINOSA, D.C.R., et al., "Efeito da incorporação de lodo de eta contendo alto teor de ferro em cerâmica argilosa", Cerâmica,v. 54, n. 329, pp. 63-76, 2008.

[51] NEVILLE, A., Propriedades do concreto, 5 ed., Bookman, Porto Alegre, 2016. 


\section{ORCID}

Denis Meira Buselatto

Matheus Chiaradia Wenzel

Gabriela Holsbach da Rocha

Sérgio Roberto da Silva

Jeferson Webber dos Santos

Jairo José de Oliveira Andrade https://orcid.org/0000-0002-9436-4010

https://orcid.org/0000-0002-1515-2459

https://orcid.org/0000-0002-4965-2187

https://orcid.org/0000-0002-9843-002X

https://orcid.org/0000-0002-3561-9896

https://orcid.org/0000-0003-2073-6763 